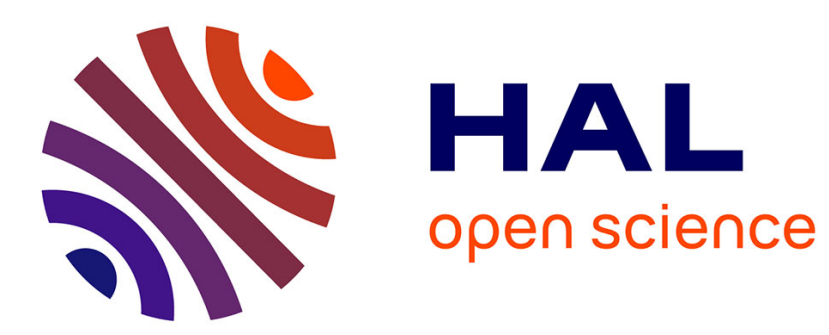

\title{
Molecular Layer Interneurons of the Cerebellum: Developmental and Morphological Aspects
}

\author{
Constantino Sotelo
}

\section{To cite this version:}

Constantino Sotelo. Molecular Layer Interneurons of the Cerebellum: Developmental and Morphological Aspects. The Cerebellum, 2015, pp.1-23. 10.1007/s12311-015-0648-x . hal-01112107

\section{HAL Id: hal-01112107 https://hal.sorbonne-universite.fr/hal-01112107}

Submitted on 2 Feb 2015

HAL is a multi-disciplinary open access archive for the deposit and dissemination of scientific research documents, whether they are published or not. The documents may come from teaching and research institutions in France or abroad, or from public or private research centers.
L'archive ouverte pluridisciplinaire HAL, est destinée au dépôt et à la diffusion de documents scientifiques de niveau recherche, publiés ou non, émanant des établissements d'enseignement et de recherche français ou étrangers, des laboratoires publics ou privés. 


\section{Molecular Layer Interneurons of the Cerebellum: Developmental and Morphological Aspects}

Constantino Sotelo $1,2,3,4,{ }^{*}$

Email constantino.sotelo@inserm.fr

Emailsotelo@umh.es

1 INSERM, UMRS_U968, Institut de la Vision, 17 Rue

Moreau, Paris, 75012 France

AQ1

2 Institut de la Vision, Sorbonne Université, UPMC Univ Paris 06, Paris, 75012 France

3 CNRS, UMR_7210, Paris, 75012 France

4 Instituto de Neurociencias, Consejo Superior de Investigaciones

Científicas (CSIC)-Universidad Miguel Hernández (UMH), Avenida Ramón y Cajal s/n, 03550 San Juan de Alicante, Spain

\section{Abstract}

During the past 25 years, our knowledge on the development of basket and stellate cells (molecular layer interneurons [MLIs]) has completely changed, not only regarding their origin from the ventricular zone, corresponding to the primitive cerebellar neuroepithelium, but also the external granular layer, but above all by providing an almost complete account of the genetic regulations (transcription factors and other genes) involved in their differentiation and synaptogenesis. Moreover, it has been shown that MLIs' precursors (dividing neuroblasts) and not young postmitotic neurons, as in other germinal neuroepithelia, leave the germinative zone and migrate all along a complex and lengthy path throughout the 
presumptive cerebellar white matter, which provides suitable niches exerting epigenetic influences on their ultimate neuronal identities. Recent studies carried out on the anatomical-functional properties of adult MLIs emphasize the importance of these interneurons in regulating PC inhibition, and point out the crucial role played by electrical synaptic transmission between MLIs as well as ephaptic interactions between them and Purkinje cells at the pinceaux level, in the regulation of this inhibition.

\section{Keywords}

Basket and stellate cells

History

Development

Chemical and electrical synapses

Manuscript for a special issue in honor of Prof. Enrico Mugnaini, Editors: Chris de Zeeuw and Marco Martina.

\section{Introduction}

Owing to its apparent organizational simplicity, the cerebellar cortex is one of the most well-known regions of the central nervous system (CNS) regarding its structural and cellular composition as well as its functionality. I will focus this review - a tribute to my friend and colleague Enrico Mugnaini-on molecular layer interneurons, the basket and stellate cells. Enrico's discovery of a new type of interneuron, the "unipolar brush cell" [1], can now be added to the short list of neuronal populations of the cerebellum, highlighting his important contributions. After recalling some historical points on the discovery of basket and stellate cells, this review highlights the current state of our knowledge concerning their genesis, proliferation, migration, cell differentiation, and synaptogenesis during development, as well as their final interconnections in adulthood.

\section{History}


It is impossible to comment on the history of the cerebellum without mentioning Cajal. In his opus magnum [2], he tried to change the name from molecular to plexiform layer, which he considered more appropriate due to being almost completely devoid of cells but containing many nerve fibers (parallel fibers) and dendrites (PC dendrites), as opposed to the granular layer which contains numerically the most important population of neurons of the whole brain, the cerebellar granule cells. In any case, the molecular layer of the cerebellar cortex - although poor in cells - contains an important population of cells already described between 1871 and 1888 by numerous histologists [3-7]. Camillo Golgi [ 8,9$]$ and his disciple Romeo Fusari [10] were the first to visualize the axon at its origin from the cell body, revealing the neuronal nature of these cells (Fig. 1a, b). Cajal [11-13] provided the most accurate description of this category of interneurons (Golgi type II), reporting in detail how the axons emerged and terminated (Fig. 1c-e). He described that the axons of the interneurons, which he called "small stellate cells", dispersed throughout the thickness of the molecular layer after their exit from the cell body or from a stem dendrite, and travelled in an anterior-posterior direction into the folia (i.e., in the sagittal plane as PC dendrites, perpendicular to the plane of parallel fibers). During their horizontal path, these axons give "numerous branches, some ascending and others descending. The ascending fibers are thin, and after several ramifications, they terminate in the molecular layer in an unknown manner, perhaps giving rise to free ends, because we could never find these thin fibers in anastomosis with the axonal branches of the most upper nerve cells. The descending branches come almost always from the vertex of certain angles present at the path of the nerve processes, they descend enlarging rapidly and branching into acute angles, forming at their ends short varicose tufts of fibers completely surrounding the bodies of Purkinje cells" (Fig. 2e). Since the most numerous branches had a deeper direction towards the PC layer and established perineuronal nets or baskets around the PC bodies, Cajal coined these cells large stellate cells or basket cells. The less numerous branches were vertical-oriented axons, ascending in the molecular layer and mostly innervating the proximal domain of the PC dendritic 
arborizations. The axons of the upper or small stellate cells also frequently terminated on the proximal compartment of the PC dendrites, although mainly in their upper regions and more rarely on PC perikarya and axon initial segments (AIS). It is important to recall that this early study gave to Cajal the first glimpse that, in contrast to Golgi's conception of the "diffuse network", the transmission between nerve cells was made by contact. In his paper published on August 15, 1888 in the "Gaceta Médica Catalana" [13], he clearly stated: "Mientras la anatomía no pruebe la existencia de conexiones directas, ésta hipótesis de la transmisión por contacto parécenos tan legítima como otra cualquiera, llevando a todas la ventaja de armonizar mejor con los descubrimientos que el método de coloración negra de Golgi ha permitido hacer en la estructura de los centros nerviosos." (While the anatomy does not prove the existence of direct connections, this hypothesis of transmission by contact seems as legitimate as any other, but with the advantage over all the others of a better harmonization with the findings that Golgi's black reaction method has allowed us to perceive on the structure of the nervous centers). It was only many years later, during the 1960s that the inhibitory effect of these neurons was disclosed [14, 15], and that GABA was identified as the used inhibitory neurotransmitter [16].

\section{Fig. 1}

a Drawing by Camillo Golgi $(1874 ; 1885)$ of the human cerebellar cortex with his own silver impregnation, the Golgi method (dendrites and cell bodies are black, axons are red). Molecular and granular layers are separated by a single row of PC bodies. In the molecular layer, it can be distinguished the dendrites of the PCs and the MLIs in deeper and superficial halves. Note that Golgi had clearly drawn the axons of these neurons emerging from the cell bodies, and that they constituted a thin bundle at the deepest part of the molecular layer. Neither pericellular nest nor "pinceaux" formations are represented. The upper right box is just a magnification of the two interneurons visible in Golgi's drawing, to illustrate the emergence of the axon (red) from the cell body. b Drawing by Romeo Fusari (1883) illustrating MLIs spreading all over the molecular layer in the human cerebellum. Fusari used the same color code than his master Golgi, and the axons are in red and also located at 
the deepest region of the molecular layer. c Parasagittal section of the cerebellar folium in pigeon stained by Cajal with the Golgi method. This drawing was published in May 1st, 1888, in his first paper on the CNS, illustrating the three-layered cortex of the cerebellum and their neuronal types. Note the presence of superficial and deeper stellate cells in the molecular layer, and that their axons end freely, forming baskets around the Purkinje cell bodies. The red arrows (added by myself) point to descending perpendicular collaterals of the horizontal axons of stellate cells located in the middle and superficial thirds of the molecular layer and ending as pericellular nests. d Drawing by Cajal corresponding to figure 377 of his opera magna (Vol. 2, 1904, page 335) A, B, large basket cells; $\mathrm{C}$, cell contributing to the formation of baskets only by its thick collaterals; D, a pericellular basket; E-G, external stellate cells with widely branched-axons. The three small red arrows (added by myself) point to ascending collaterals of the basket cell axons. e Cajal drawing of "pinceau" formations in Golgi impregnated cerebellum. This drawing published in $1888 \mathrm{~b}$, his figure 17 , reports the first description of the pinceaux, Cajal wrote: "Only one detail will be added to the description given in our previous work: The twigs of the fringes, not only surround the body of the Purkinje cell, but also extend beneath it, accompanying by some distance the cylinderaxe of Deiters (today the axon), and ending as the tips of the thin threads of a brush" 


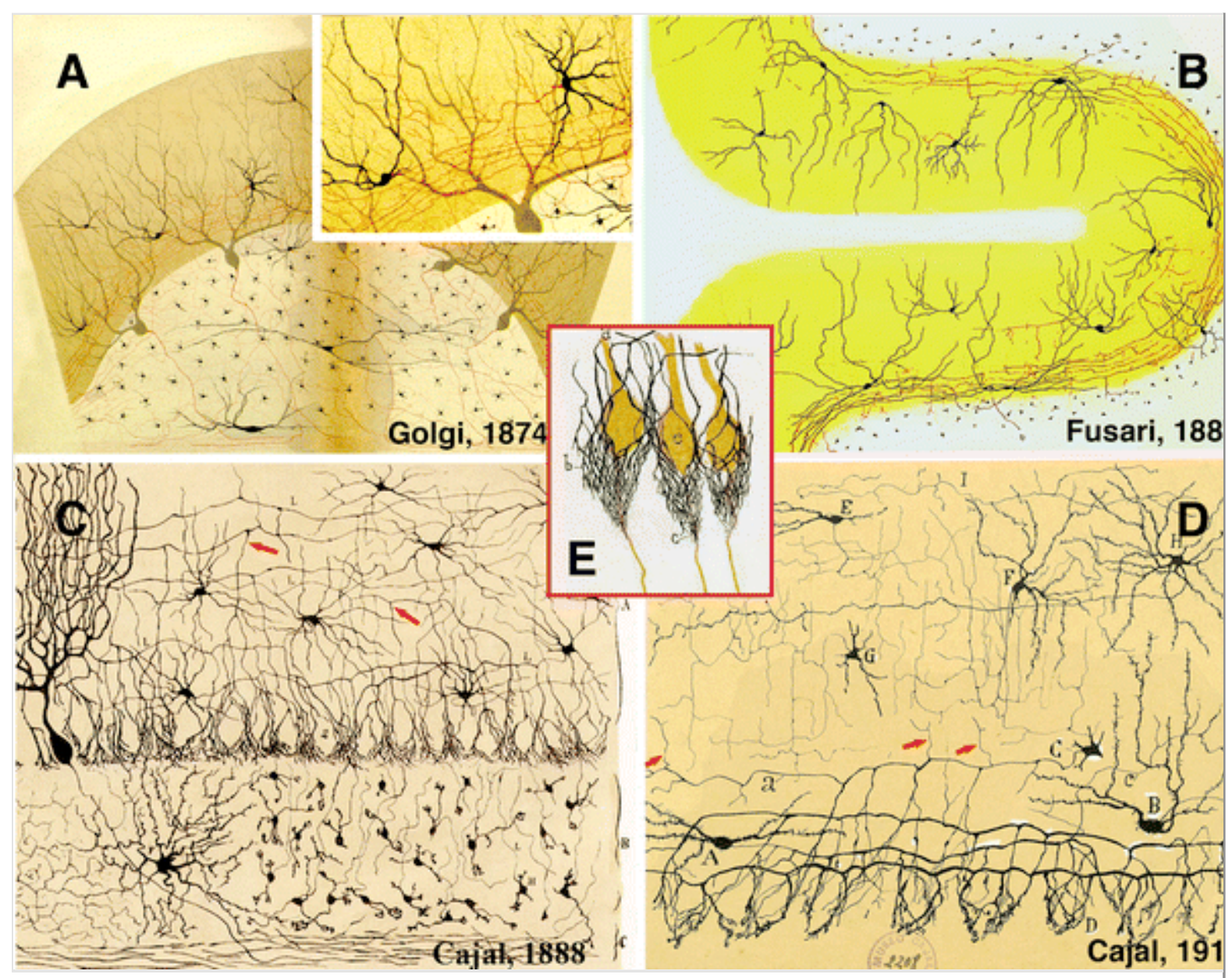

Fig. 2 
Microphotographs of anti-parvalbumin and anti-quail double labeled sections. a Low magnification of a coronal section taken with the fluorescein filter to reveal quail cells. The cerebellar midline is indicated by the dotted line. Note that in the grafted side (left) there is a high immunoreaction in the molecular (ML) and Purkinje cell layers as well as in the white matter. The reactivity is lower in deep internal granular layer (IGL) and null in the external granular layer. Note numerous immunopositive cells in the molecular layer of the contralateral hemicerebellum (right) but none in other layers. b and c High magnification of a sagittal section taken from the hemicerebellum contralateral to the graft of another chimera. Both panels illustrate the same field. The arrows point to four MLIs that have tangentially migrated through the midline. They are MLIs since they are labeled both by the anti-quail antibody (b) and by the anti-parvalbumin (c). Note labeled PCs of host origin (P) Scale bars: $A=150 \mu \mathrm{m} ; \mathrm{B}, \mathrm{C}=25 \mu \mathrm{m}$. Figures taken from the paper of Alvarez-Otero, Sotelo and Alvarado-Mallart, 1993 

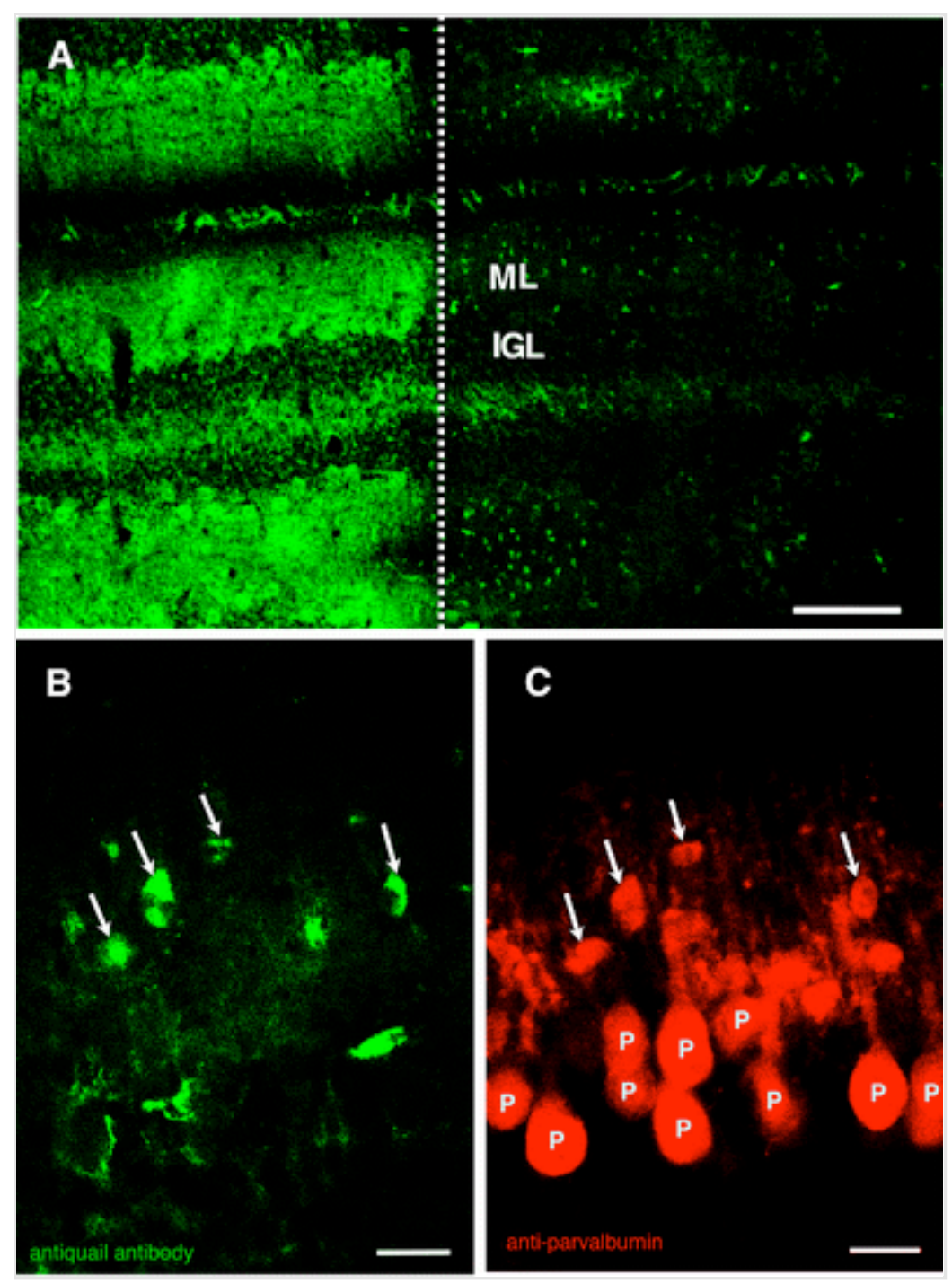

Therefore, basket and stellate cells are of great historical interest, as Cajal's description of these cells initiated the long battle to convince scientists that nerve cells were independent cells that communicate among themselves by contact. The axonal baskets have a perineuronal location, in contiguity not in continuity with the PC body or with other neuronal processes. The banner under which Cajal fought all his life was "among neurons only contiguity not continuity." It took 56 years to fulfill the wishes of Cajal in proving the existence of contact transmission, when George Palade and Sandy Palay [17] reported the first electron microscope image of the central synapse, with the presence of two membranes, one surrounding the presynaptic and another the postsynaptic element, separated by a space of about 30 to $35 \mathrm{~nm}$ or synaptic clef. Neurons are indeed independent units. 
The theoretical dispute between the possibility that the basket and stellate cells constitute two different populations of GABAergic interneurons or only a single population started early in the 1970s. The proponents of dichotomy supported it by stating that inhibitory neurons can be classified on the affinity of their axons for a particular region of their target cells. Therefore, basket and stellate cells are obviously two different populations because their axons have very different targeted domains. Indeed, the axons of stellate cells only contact with the dendrites of Purkinje cells (PCs), while those of basket cells form pericellular nests around the perikarya of PCs and end forming pinceaux on the initial segments of their axons (AIS), respectively. However, this explanation was not completely convincing. Long before the start of the controversy exceptions were reported concerning the postsynaptic targeting of stellate and basket cell axons. Thus, Cajal [12, 18] revealed that basket cell axons have ascending collaterals destined to contact PC dendrites. Furthermore, his early drawings suggested that stellate cells located at the center of the molecular layer contributed, through long descending axon collaterals, to pericellular nests and pinceaux impregnated samples. These two types of interneurons can contribute not only to the baskets, but also to the pinceaux formations, suggesting that both interneurons could belong to the same population, as Cajal assumed in his first paper on the cerebellum calling both of them small stellate corpuscles of the molecular layer [11, 18]. These results have been corroborated several times, either by the study of the distribution of identified descending collaterals of the stellate axons in Golgi impregnated material $[19,20]$ and also in combined Golgielectron microscopy [21] or through a multivariate analysis of a large number of three-dimensional morphological features of dendrites and axons obtained from Golgi impregnated stellate and basket cells [22]. However, the question remains unanswered. Many people like myself, researchers of the morphology of the cerebellum, support Cajal, Mugnaini, and many others in the hypothesis that both interneurons belong to the same population. However, 5 years ago, Schilling and Oberdick [23] mined the Allen Mouse Brain Atlas to obtain information about gene expression in cerebellar interneurons and reached an opposite conclusion. They identified 90 genes highly 
expressed in cortical inhibitory interneurons. Some of them were differentially expressed in those interneurons lying in deeper zones (basket) and those located in the most superficial region (stellate) of the molecular layer and concluded that basket and stellate cells are molecularly distinct. This discrepancy will surely be resolved very soon, since with genetic engineering in mice, new Cre, and inducible CreER knockin driver lines would be generated to unravel the diversity of cerebellar GABAergic interneurons, as it has been done for cerebral cortical interneurons [24]. In the following text, and pending a final solution, I compile both classes of interneurons into a single category under the generic name of "molecular layer interneurons" (MLIs).

\section{Origin and Migration of Cerebellar Interneurons}

The cerebellum is one of the rare central regions that possesses two different germinal neuroepithelial: the ventricular zone of the fourth ventricle (VZ) or the primitive cerebellar neuroepithelium, and the upper rhombic lip (URL), which gives rise to the external granular layer (EGL), both derived from the alar plate of rhombomere 1 (Rh1). Classical histological studies strongly suggested that the MLIs could not derive from the $\mathrm{VZ}$ since the majority of the neurons of this layer appear postnatally when VZ mitotic activity is absent. Therefore, it became evident that the conjecture of the nineteenth century neuroanatomists such as Schaper [25], Athias [26], and even Cajal [2] was corroborated and that the basket and stellate cells were considered as generated from the precursors in the EGL. This conclusion, strongly supported by tritiated thymidine labeling experiments done during the 1960s which showed that MLIs originated during the first postnatal week [27], was later proven wrong.

The first indications that this assumption was incorrect arose from studying the cerebella of quail and chick chimeric embryos [28], where it was possible, using the Feulgen and Rossenbeck [29] DNA histochemical reaction, to distinguish between quail and chicken cells because the nucleus in quail cells contains a large amount of heterochromatin associated with the nucleolus that is absent in chick 
cells [30]. In the chimeras, PCs systematically exhibit the same genotype as the VZ surmount, as well as in the vast majority of the neurons and glial cells of the molecular layer. The EGL, on the other hand, presented the same genotype as the granule cells. Thus, it was evident that MLIs did not possess the same origin as granule cells. A few years later, in collaboration with Cuca Alvarado-Mallart and one of her students, Rosa Alvarez-Otero [31], we used a similar approach, but in our quail/chick chimeras, one section out of three was serially mounted for reconstruction of the chimeric cerebella. This series was stained with the Feulgen and Rossenbeck reaction to correlate between precise regions of the germinal neuroepithelium and defined areas of the adult cerebellum to determine the origin and normal dispersion of postmitotic neuronal cells. In the remaining series, the sections were double-immunostained with a marker of MLI (anti-parvalbumin mab) (Fig. 2c), and a marker of quail cells (a specific rabbit anti-quail polyclonal antibody [32]) (Fig. 2a, b), to identify the basket and stellate cells. The results fully corroborated the conclusion reached by Hallonet et al. [28] that MLI did not originate in the EGL. In addition, a new and important result was obtained: MLIs were the only neuronal types able to cross the cerebellar midline and settle in the contralateral hemicerebellum (Fig. 2a-c), proof of their extended dispersion during their migration.

The same year of our publication with quail/chicken chimeras, Napieralski and Eisenman [33] analyzed the development of the cerebellum in a mutant mouse line with a sporadic mutation affecting mostly its anterior lobes, the meander tail mutant (mea/mea). The severe atrophy of the anterior cerebellum in this autosomal recessive mutation is mainly characterized by the atrophy of the cerebellar anterior lobe due to a failure of granule cell development of unknown cause [34]. Despite the failure of the EGL and the absence of granule cells, MLIs exhibit normal numbers and appearance. Therefore, this study together with the previous ones with quail/chicken chimeric cerebella clearly disqualified the EGL progenitors as the source of basket and stellate cells; however, they do not provide any clue concerning the location of such precursors. Moreover, more recent 
transplantation experiments by Gao and Hatten [35] provided conclusive results to exclude the EGL as the germinal neuroepithelium containing the MLI progenitors. Gao and Hatten [35] reported that the implantation of embryonic day 13 cerebellar precursor cells into the EGL of early postnatal mouse gave rise to all the major cerebellar cell types, including the MLI. In contrast, if the implantation was performed with primary EGL progenitors, only granule cells were generated. These results also indicated that the MLIs could not be generated from progenitors of the EGL, although their location still remained unknown.

Important data on the origin, proliferation, and migration of MLI arise from the work of James Goldman's group [36, 37]. These researchers injected replication deficient-retrovirus carrying de $\beta$-galactosidase gene either in the deep cerebellar tissue or in the EGL of P4-P5 rats. As a result, $\beta$-gal positive interneurons were detected 20 days after injection exhibiting the typical features of basket and stellate neurons within the molecular layer and Golgi cells in the inner granule cell layer in the rats injected in the deep cerebellar tissue, close to the VZ. On the other hand, EGL injections did not label the MLI nor Golgi cells, and only granule cells of the internal granular layer were labeled. The study pointed to the fact that MLI progenitors proliferated in the presumptive white matter of deep cerebellar tissue and migrated towards the cortex, where they ended proliferation and matured. Therefore, as opposed to granule cells, MLIs were not generated in the EGL, but in or near to the VZ (the section referring to proliferation will comment that they are generated from progenitors in the VZ). One important result of Zhang and Goldman [37] was to disclose viral injections at P4-5 labeled progenitors which in a few days produced neurons and glial cells, whereas those injected at P14 provided only glia. The unresolved question was to determine if the progenitors were multipotential, generating astrocytes, oligodendrocytes, and neurons or if they were already committed to a neuronal or glial fate.

Another interesting observation in this study [37] was that labeled cells present in the white matter of the deep cerebellar tissue were neuroblasts with the ability to proliferate and not young postmitotic 
neurons. This rare behavior of neuronal progenitor able to start their migration before finishing their proliferative period is similar to what takes place in the rostral migratory stream between the subventricular zone of the anterior pole of the lateral ventricle and the olfactory bulb [38]. Finally, Zhang and Goldman [37], based upon the fact that the study of parasagittal sections showed that labeled progenitors of the white matter remained confined to only a few sections at both sides of the injection site and did not spread throughout the whole cerebellum, they reached the conclusion that in their migration the neuroblasts followed cues strictly oriented in the sagittal plane, taking axonic orientations. Once in the presumptive white axes of the cortical folia, the young postmitotic interneurons could migrate radially through glial fibers, reaching the molecular layer, where they acquired their final phenotype. Moreover, Zhang and Goldman [37] noticed that from all types of labeled cells encountered (MLIs, Golgi cells, astrocytes, and oligodendrocytes), the MLIs were the most widely dispersed, suggesting that once in the molecular layer they migrated tangentially, even across the midline leaving the quail graft to enter into the chick genotyped region as indicated by the aforementioned quail/chick chimeric embryos $[28,31]$. The above reported data provide an explanation to the apparent paradox between ancient and actual neurobiologists. Indeed, the absence of mitotic figures in the $\mathrm{VZ}$ is the result of the prenatal exit of most if not all MLI progenitors from the $\mathrm{VZ}$ and that during their long migratory journey they continue to proliferate and differentiate. In other words, the lack of postnatal mitosis in the VZ did not prevent the MLIs to have their origin in the VZ. Therefore, GABAergic cerebellar interneurons, together with the subventricular zone (SVZ) at the anterior horn of the lateral ventricles, where neuronal proliferation is lifelong, and new granule and periglomerular cells are continuously added to the olfactory bulb through their migratory road the rostral migratory stream (RMS) [38, 39], are the best known exceptions to the general developmental rule that it is only after the end of their proliferation that the young postmitotic neurons start migration. Indeed, in these two locations, cerebellar prospective white matter and RMS, neuroblasts leave their germinal neuroepithelia, and migrate while dividing to reach their 
ultimate location.

Next, in this temporal progression of understanding MLI development, we have arrived to the end of the twentieth century and to the discovery that the homeobox gene Pax2, a key gene in midbrain/hindbrain specification during early CNS development, is also expressed in the cerebellum, hindbrain, and spinal cord (from E12 to over P15). Maricich and Herrup [40] showed that, during this late period of cerebellar expression, the role of Pax 2 shifts from the specification of an anatomical field to become a cell-specific marker of both cortical and deep nuclei GABAergic interneurons. Thus, basket, stellate, and Golgi cells transiently express Pax2 in the white matter and during their migration to enter into the cortical region, suggesting that Pax 2 expression is maintained during most of their proliferative period, during all their migration, and is only lost at the precise moment of their final division and the beginning of their synaptic maturation, marking the acquisition of the inhibitory interneuron identity. With this specific cell marker in hand, it was possible to consolidate previously acquired notions concerning the white matter origin of MLIs, the neuroblastic nature of the migrating progenitors, and an internal-to-external movement of these interneurons during their final neuronal differentiation.

The use of transgenic mice, together with the improvement of the morphological analysis by video recording of migrating neurons, allowed the detailed study of MLIs migration, not throughout the presumptive white matter where it is assumed that the migration was of neuronophilic type, using as migratory substratum efferent and afferent axons, but from their arrival at the molecular layer to their final locations. Cameron et al. [41], although their study did not change the basic ideas about this migration, have clarified the process by sequencing the MLIs movement into four phases. Phase I is the continuation of the radial migration of the incoming neuron from the interface between the inner granular layer and the molecular layer that later pursues its outwards displacement to the surface of the latter. Phase II takes place at the top of the molecular layer and corresponds to 
a rostrocaudal tangential migration. At the end of phase II, the cells change direction from horizontal to vertical again, and start their phase III, which corresponds to a radial migration. Finally, phase IV is a new tangential migration in the rostrocaudal direction as in phase II, but instead of taking place at the top of the molecular layer the neurons migrate at the middle of the layer, and the speed of the migration is extremely slow. Radial mixed with tangential migrations was suggested not only in the previously mentioned publications [28, 31, 37], but also in several others using transgenic mice in which green fluorescent protein (eGFP) was expressed selectively in GABAergic cells, such as GlyT2 gene promoter-driven GFP (Fig. 5b, C of [42]) or GAD65 gene promoter-driven GFP [43] originated from the colony obtained at the Department of Gene Technology and Developmental Neurobiology, Institute of Experimental Medicine, Budapest, Hungary, by Drs. Ferenc Erdélyi and Gábor Szabo [44] (Fig. 3a-d). In the two instances, GABAergic interneurons of the developing mouse cerebellar cortices express GFP allowing their visualization in a Golgi-like manner. In the transgenic mice I had studied [43], transgene expression was spatiotemporally regulated. Whereas in newborn pups almost all PCs expressed GFP (Fig. 3d), the expression disappeared from these neurons rather quickly. Therefore, between $\mathrm{P} 5$ and $\mathrm{P} 7$, the expression was progressively lost and only less than $6 \%$ of PCs remained GFP+ during the second week of life (Fig. 3a, b). In contrast, MLIs maintained GFP expression until adulthood (P21 was the latest time examined). At P10 and P11, the cells were dispersed within the whole molecular layer, although the density was higher at the most superficial part of the layer, where they did not present vertical or oblique orientations, but are disposed following a horizontal mediolateral direction (Fig. 3a). The bipolar appearance of these neurons, their parallel disposition, and their upper location mimic those of tangentially migrating neurons in other CNS regions and might correspond to the phase II of Cameron et al. [41]. For the time being, migration processes seem identical in basket and stellate cells, probably due to the lack of specific markers to identify them properly, which could also be considered as indirect argument in favor of their identical nature.

Fig. 3 
These microphotographs illustrate GFP + neurons in parasagittal sections of postnatal cerebella of transgenic GAD65-GFP mice (Erdélyi et al. 2002) in newborn pups (c, d), P11 (a), and P15 mice (b). a, b Each panel represents a stack of confocal images of GFP (green autofluorescence) illustrating the density of molecular layer interneurons, and the low level of expression and rarity of autofluorescent PCs in P15 transgenic mice (b), enough however to visualize the "pinceaux" around the PC AIS (white arrows). In (a), the fluorescent interneurons at the subpial level exhibit bipolar morphologies (arrows) like neurons in their tangential migration. One of the MLI (pointed by a crossed arrow) is in its radial migration. c White matter in a medial parasagittal section of a newborn transgenic pup, labeled with anti-Pax2 antibodies (red). Note, at the center of the micrograph, the presence of three interneurons doublemarked by GFP and the anti-Pax 2 antibody. The vast majority of Pax 2 positive nuclei do not express the GFP, and in one of the GFP+ interneurons (asterisk), the nucleus is Pax2 negative. d Midsagittal section of a newborn transgenic cerebellum passing through the velum medullaris, same material than (c). Double labeled cells are present in the velum (see boxed area with a higher magnification) and in the area of the white matter confluent with the velum (asterisks). The asterisk in the velum medullaris has been reproduced in the boxed area to indicate location of double-labeled cells. (These four micrographs have not been published before). Scale bar $=54 \mu \mathrm{m}$ for $\mathbf{a}, \mathbf{b}$, and $\mathbf{c}, \mathbf{d}=194 \mu \mathrm{m}$ 

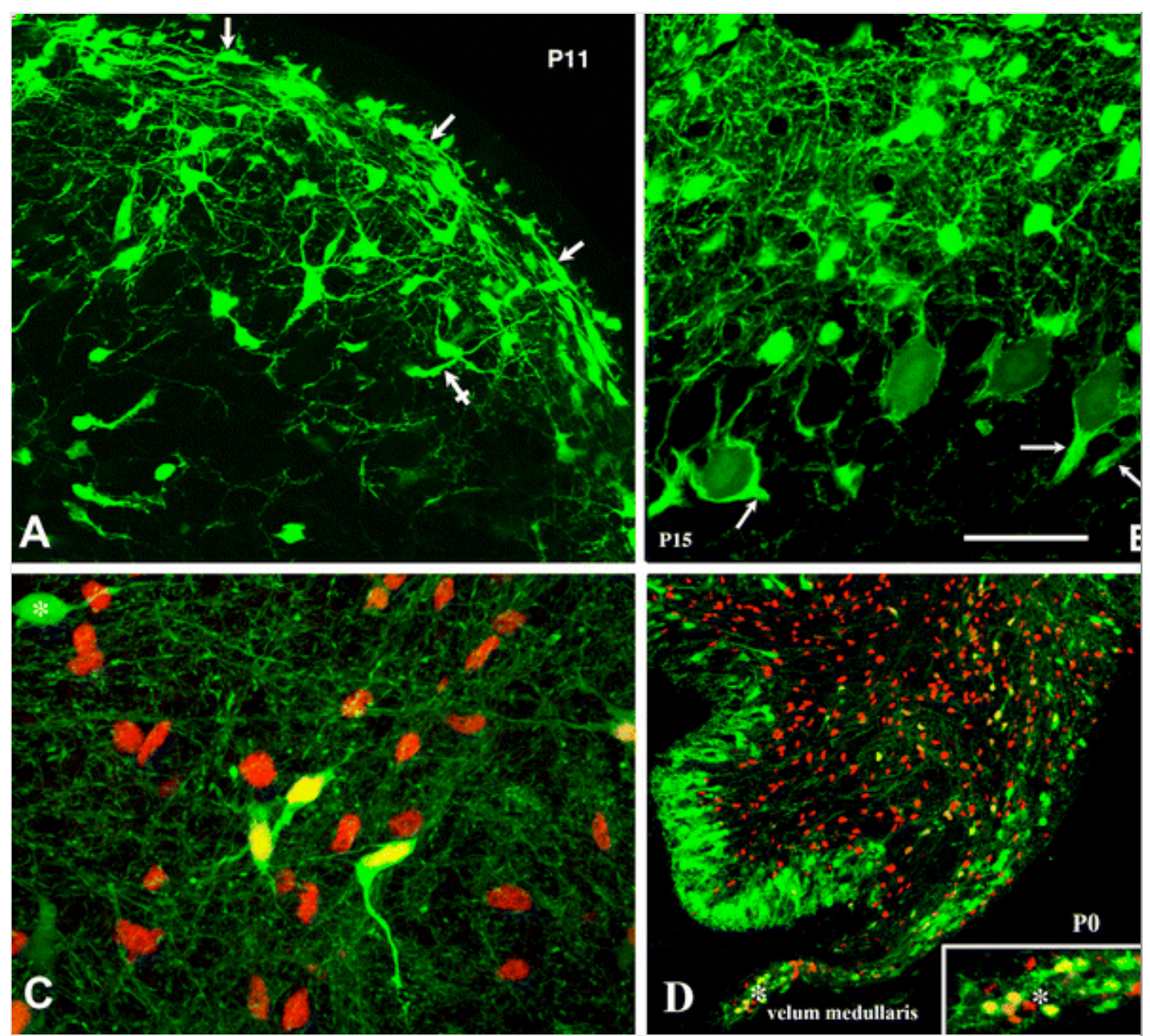

Some of these sections of cerebellum were immunostained with rabbit anti-Pax-2 antibodies to identify MLIs. When examining parasagittal sections of newborn transgenic mouse cerebellum (Fig. 3c, d), it was observed that the molecular layer was covered with GFP expressing PCs, but as expected MLIs were practically absent from the cortical zone. In addition, the central white matter was filled with Pax-2 positive nuclei but only some of them had a green fluorescent cytoplasm (Fig. 3c), suggesting a lack of simultaneity among the expression of both markers. Detailed examination of mid-parasagittal sections cutting longitudinally the anterior medullary velum that is between the vermis and the midbrain revealed that among the numerous cells that populate this structure many were GFP+ and some of them were double labeled with a yellow nucleus and a green cytoplasm (Fig. 3d, lower box). Finally, as expected, cells with only red nuclei $(\operatorname{Pax}-2+)$ were also 
observed in both, presumptive white matter and velum medullaris (Fig. 3c, d).

What types of cells enter or leave the cerebellum throughout the velum medullaris? My first impression was to consider the possibility that, as it is the case for the cerebral cortex, inhibitory interneurons may also have an extracerebellar origin. However, all efforts done to assert this possibility failed (in vitro organotypic cultures of embryonic cerebellum separated from its brainstem and quail/chick chimeras' unpublished results). Our results with the chimeric embryos demonstrated that only oligodendrocyte progenitors can have an extracerebellar origin, derive from the parabasal plate of the mesencephalon and enter the cerebellum through the velum [45]. Moreover, the analysis of the effect of the bHLH transcription factor Asll in developing cerebellum [46] reported that loss of Asll function provokes a broad reduction in the number of GABAergic interneurons and oligodendrocytes but increases the number of astrocytes. Although these results may indicate some filiation between MLI and oligodendrocytes, the researchers make very clear that MLIs and astrocytes are generated from progenitors in the $\mathrm{VZ}$, whereas those for oligodendrocytes are located outside the cerebellum, without identifying their origin. Nevertheless, it has been recently shown that at least some of the cerebellar oligodendrocytes emerge from rhombomere- 1 and, therefore, they are of cerebellar origin [47]. In any case, Grimaldi et al. [46] conclude that MLIs and oligodendrocytes are not lineally related and that $\mathrm{Ascll}$ has no role in the differential choice between these two cells types, strongly suggesting that oligodendrocytes should not express Pax2. Therefore, the identity of the cells with nuclei expressing Pax2 and GFP+ cytoplasm (Fig. 3d), transiting through the velum medullaris of newborn (P0) GAD65-GFP transgenic mouse pups, remains for the time being evasive.

\section{Genetic Mapping of the Germinal Ventricular Zone at the Origin of the MLIs and Proliferative Behavior of their Progenitors}

After demonstrating that the molecular layer interneurons did not 
originate from the EGL, it was accepted that the latter only produced granule cells, the most numerous neuronal population of the whole brain. The conclusion was that the remaining cerebellar neurons, cortical and nuclear, were produced by the primitive cerebellar neuroepithelium, the VZ. This idea was progressively verified when, using molecular biology techniques and transgenic mice, the genetic fate-mapping analysis allowed the identification of the transcription factors that regulate the specification of the different cerebellar populations and the acquisition of their neuronal identities. One of the first master genes discovered was the bHLH type transcription factor Math1 [48], a mouse homologue of atonal in Drosophila (currently known as Atohl) that commands the neuronal fate in the EGL by granule cell progenitors, and where its inhibition prevents the formation of granule cells. Other URL derivatives in the EGL also regulated by the Atoh1 locus give rise to the large projection neurons of the deep cerebellar nuclei (DCN) [49, 50]. Robert Hevner's group [51] corroborated that the majority of the DCN neurons were produced in the URL by cells expressing Pax6, Tbr2, and Tbr 1 genes and, through a subpial tangential migration within the EGL, entered into the nuclear transitory zone (NTZ) to become glutamatergic DCN projection neurons.

An important advancement in the history of the genetic regulation of MLIs in their acquisition of their neuronal fates was made thanks to Mikio Hoshino et al. [52]. Using a Cre-loxP recombination-based lineage tracing studies, the authors discovered another bHLH type transcription factor, Ptfla, but this one expressed in the cerebellar VZ. In conditional mutants in whom this gene was inactivated from the VZ, only a vestigial cerebellum remained (the mutation was coined cerebelless), containing the deep cerebellar nuclei, while lacking the whole cerebellar cortex. The primary defect in this mutant was the lack of GABAergic neurons that never developed. Therefore, all the inhibitory GABAergic neurons of the cerebellum, whether they were medium-sized deep cerebellar nuclear projection neurons (nucleoolivary and nucleo-cortical) or small nuclear interneurons, as well as the cortical projection neurons (Purkinje cells) and cortical local circuit 
neurons (stellate, basket, Lugaro, Golgi and candelabrum cells) originated from the alar plate of the neural tube at the rhombomere 1 (Rh.1), the so-called primitive cerebellar neuroepithelium (VZ). The fact that PCs were not generated in these conditional mutant mice explains the main reason for the phenotype of this mutation, since PCs and their secretion of Shh are required for the proliferation of granule cell progenitors [53], therefore without PCs there are no granule cells and no cerebellum.

The interest of this double source of cerebellar neurons is that a simple change of the bHLH type of transcription factor is enough to invert the neuronal phenotype corresponding to glutamatergic or GABAergic neurons. Thus, if the Ptfla gene is inactivated in the VZ, the fate of neurons produced from the VZ is changed to that of granule cells. In conclusion, the dichotomy of the cerebellar germinal neuroepithelia is at the origin of the dichotomy between excitatory and inhibitory neurons. While all the Ptfla + GABAergic neurons are generated in the VZ, all glutamatergic neurons derive from the URL and express Atohl as the specific transcription factor.

A more recent study by Alexandra Joyner and collaborators [54] used a powerful tool to identify cells derived from the cerebellar VZ, the genetic inducible fate mapping (GIFM) using the AscllCreER-knockin mice. With this technology, it was possible to mark neuronal PCs and GABAergic interneurons at their last cell division either in the $\mathrm{VZ}$ or the presumptive white matter. This approach has provided more precise information about the location and the timing of proliferation in cortical inhibitory interneurons, including less frequent cells such as the Lugaro cells and candelabrum. Although all these neurons originate from the $\mathrm{VZ}$, these new birth-dating studies show that Golgi cells are the first to arise in the VZ from E14-E18, whereas the remaining cells appear at early postnatal stages (P7-P10) from the white matter, basket, and candelabrum before stellate. It is important to note that Ptfla is mainly expressed in postmitotic VZ cells, since in double marked preparations, Ptfla is expressed almost exclusively in non-mitotic cells that are unable to be double marked by bromodeoxyuridine (BrdU) [55], and 
cannot be directly involve in the genesis of GABAergic interneurons. Moreover, Huang et al. [55] have also shown that progenitor expansion in the cerebellar VZ results from proliferation of radial glial cells, a process that is regulated by Shh signaling. Surprisingly, it has been recently shown that the Shh secreted by PCs also plays a role in the proliferation of MLIs' progenitors by maintaining the activity of their PWM niches [56]. For these authors, PCs are the key elements in the production of functionally opposed granule cells and MLIs aimed at maintaining a "bidirectional signaling axis" to balance the excitatory synaptic activity by inhibition.

Kathleen Millen and her group [57] have determined the importance of the roof plate of rhombomere 1 in the specification of cerebellar neuronal identities. This signaling center contributes to the cerebellar patterning by the regulation of progenitor proliferation and cell position within the cerebellar anlage. This process, also regulated by transcription factors, subdivides by E12.5 the cerebellar VZ into four main domains from $\mathrm{c} 1$ to $\mathrm{c} 4$, providing an early molecular map of the cerebellum. The purpose of this genetic mapping is to examine more closely the process of cell commitment and to determine the precise site of origin of each of the neuronal populations that populate the adult cerebellum. While $\mathrm{c} 1$ domain corresponds to the URL and is defined by Atoh1 expression, and $\mathrm{c} 2$ is located above the broad region of the $\mathrm{VZ}$ expressing Ptfla (called pc2), the other two, c3 and c4, were only characterized by the expression of Lmxla and $L h x 1 / 5$, respectively, although the researchers could not discern the type of neurons they generated. This early mapping has been more recently refined and, concerning our MLIs, $\mathrm{c} 2$ has been subdivided into a dorsal and a ventral part (c2d and $\mathrm{c} 2 \mathrm{v}$ ) by the expression of corl2 in $\mathrm{c} 2 \mathrm{~d}$ and Pax 2 in $\mathrm{c} 2 \mathrm{v}$. This differential expression allows the correlation of $\mathrm{c} 2 \mathrm{~d}$ (the Ptfla, corl2 expressing subdomain) with PCs [58] and c2v (the Ptfla, Pax2 expressing subdomains) with Lugaro, Golgi, basket and stellate cells, that is to say the major classes of GABAergic interneurons in the cortex of the cerebellum [40]. Therefore, it is today generally accepted that the cerebellar $\mathrm{VZ}$ can be considered as a complex mosaic composed of numerous subdomains, each one specified to give rise to a precise 
GABAergic neuronal population or subpopulation (see in [59]).

\section{Specification and Differentiation of Molecular Layer GABAergic Neurons}

The late Ferdinando Rossi and his collaborators, using the transplantation of neural progenitor cells into isotopic, isochronic, heterotopic, and heterochronic environmental conditions, have performed, without a doubt, the most outstanding work on this topic. The investigation was started years ago in my laboratory, when Ferdinando was on an extended stay in Paris and was working with my student Alexander Jankovski [60]. Our aim was to determine the nature of some of the mechanisms regulating the genetic restriction leading to the acquisition of the vast diversity of neuronal phenotypes encountered in the adult brain. Is the acquisition of cell identity the result of a progressive restriction of multipotentiality $[61,62]$ ? Or is the final commitment induced by environmental factors affecting daughter cells soon after the S-phase of the last division of its progenitor as postulated by McConnell and Kaznowski [63] for neocortical progenitors? Cell transplantation was the selected approach to solve this problem, since it offers a simple way to change the cellular environment of the grafted progenitors by the way of isochronic or heterochronic and isotopic or heterotopic transplantations. The existence of the two cerebellar germinal epithelia, VZ and EGL, provided a simple way to analyze the role of cellular environment in the commitment of MLIs, through mixed cell suspensions grafted to adult cerebellum. Therefore, cells derived from postnatal mouse cerebellar cortex (P4) and embryonic cerebellar primordium (E12) were mixed together and co-grafted to the ventricles of adult recipient mice. To identify cells arising from postnatal cerebellar progenitors, we used several transgenic mouse lines, in which the lacZ reporter gene was expressed by different cerebellar neuronal populations. These lines were $\beta 2 \mathrm{nZ3} 3^{\prime}$ [64], generated with regulatory elements of the $\beta 2-$ microglobulin gene $(\beta 2 \mathrm{~m})$ and the lac $Z$ reporter gene in which Xgal labeling was confined to cell nuclei owing to "nls" targeting of transgene expression. In these mice, the transgene is expressed in specific sets of developing and adult neurons (in the case 
of the cerebellum it appears only in basket, stellate, and granule cells); L7BG1, expressed by PCs [65]; and neuron-specific enolase, expressed as cytoplasmic spots of variable sizes by all neurons [66]. Nine to 60 days after transplantation, the engrafted cells, although organized heterogeneously, evolved to form mini cerebellar structures, often with segregation of cortical and nuclear regions. In transplants with $\beta 2 \mathrm{nZ3}{ }^{\prime} 1$ transgenic cells, of interest for our aims, labeled cells were always scarce in the molecular layer but abundant in the IGL, where they were intermingled in variable proportions with unlabeled cortical cells. Quantitative analyses to determine the size of the labeled neurons allowed us to identify the cells. The vast majority of the Xgal-positive cells (Fig. 4a, b) were small neurons less than $8 \mu \mathrm{m}$ in diameter, with round nuclei and thin cytoplasm exhibiting features of cerebellar granule cells. The remaining cells were larger up to $15 \mu \mathrm{m}$ in diameter, sharing their ultrastructural features with MLIs (Fig. 4d), and exhibiting parvalbumin immunoreactivity (Fig. 4c). Therefore, cells derived from postnatal cerebellar progenitors acquire two different adult phenotypes: (1) granule cells and (2) MLIs. In conclusion, both types of progenitors appear to be strictly specified at the time of grafting, and neither their identities nor the expression of their major distinctive features was significantly influenced by presumptive neurogenic signals produced by the nearby embryonic cerebellar cells.

\section{Fig. 4}

Transplantation experiments to determine the role of the microenvironment in the neuronal fate of basket and stellate cells. a This micrograph shows the morphology of Xgal-positive cells in $\beta 2 \mathrm{nZ3} 1$ derived minicerebellar grafts, and the almost constant ectopic location of MLIs, which remain in the inner granule cell layer mixed with granule cells. Note the different sizes and staining intensities of the labeled nuclei. b Histogram showing the distribution of the maximum diameter of 404 labeled nuclei and the results of the morphometric analysis. It clearly shows the occurrence of two classes of Xgal-positive cells: one with an average nuclear diameter of $5.86 \mu \mathrm{m}$ and another of $10.13 \mu \mathrm{m}$, corresponding respectively to granule cells and MLIs. c A $\beta Z n Z 3$ '1derived graft stained by double immunofluorescence for anti-parvalbumin (red) and anti- $\beta$ galactosidase (green) antibodies. Purkinje cell 
immunofluorescence for parvalbumin is hidden by the superimposition of a light anti-calbindin immunoperoxidase reaction. Several transgeneexpressing cells are present in the IGL of the cortical folium, among which doubled cells (arrowheads) are characterized by yellow nuclei surrounded by a halo of red cytoplasm. The arrow points to cell with a green nucleus (transgenic, therefore grafted) probably too large to be a granule cell, but since it is devoid of red cytoplasm does not correspond to a MLI and could be a Golgi cell. d Ultrastructural features of a medium sized Xgal-labeled cells in $\beta 2 \mathrm{nZ3}$ '1-derived grafts Arrowheads point to the nuclear and cytoplasmic precipitate produced by the X-gal reaction product. The arrow points to a synapse formed by a presumptive parallel fiber varicosity on an emerging dendrite, validating the neuronal nature of the labeled cell. ( $\mathbf{f}$ and $\mathbf{e}$ ) Double-labeled parasagittal section passing trough the rostral migratory stream (RMS) of an adult mouse that received a graft of P6 cerebellar cells 21 days before perfusion. $\mathbf{f}$ Anti-ßgal antibodies to stain the nuclei of the grafted cells. e Anti-parvalbumin to visualize grafted MLIs. The numbers in (f and e) identify double-labeled cells in the caudo-dorsal zone of the RMS from its emergence at the lateral ventricle. Although most of the labeled cells are within the RMS, some of them have left the pathway and remains in its vicinity. Note the stellate shape of the parvalbumin positive cells. a-d taken from Jankovski, Rossi and Sotelo (1996), (e and f) Jankovski and Sotelo (1996). $\mathbf{g}$ This micrograph illustrates a small area of a section of an adult $\beta 2 \mathrm{nZ3}$ ' 1 cerebellum double labeled with X-gal histochemistry and anti-neurofilament antibodies. Blue nuclei $(\mathrm{X}$-gal + ) correspond to MLIs in the molecular layer (ML) and granule cell clusters under the pericellular baskets immunostained by the anti-neurofilament antibody (brown). Scale bar indicated on each bar. The bar in (c) also indicates the magnification in (g) 

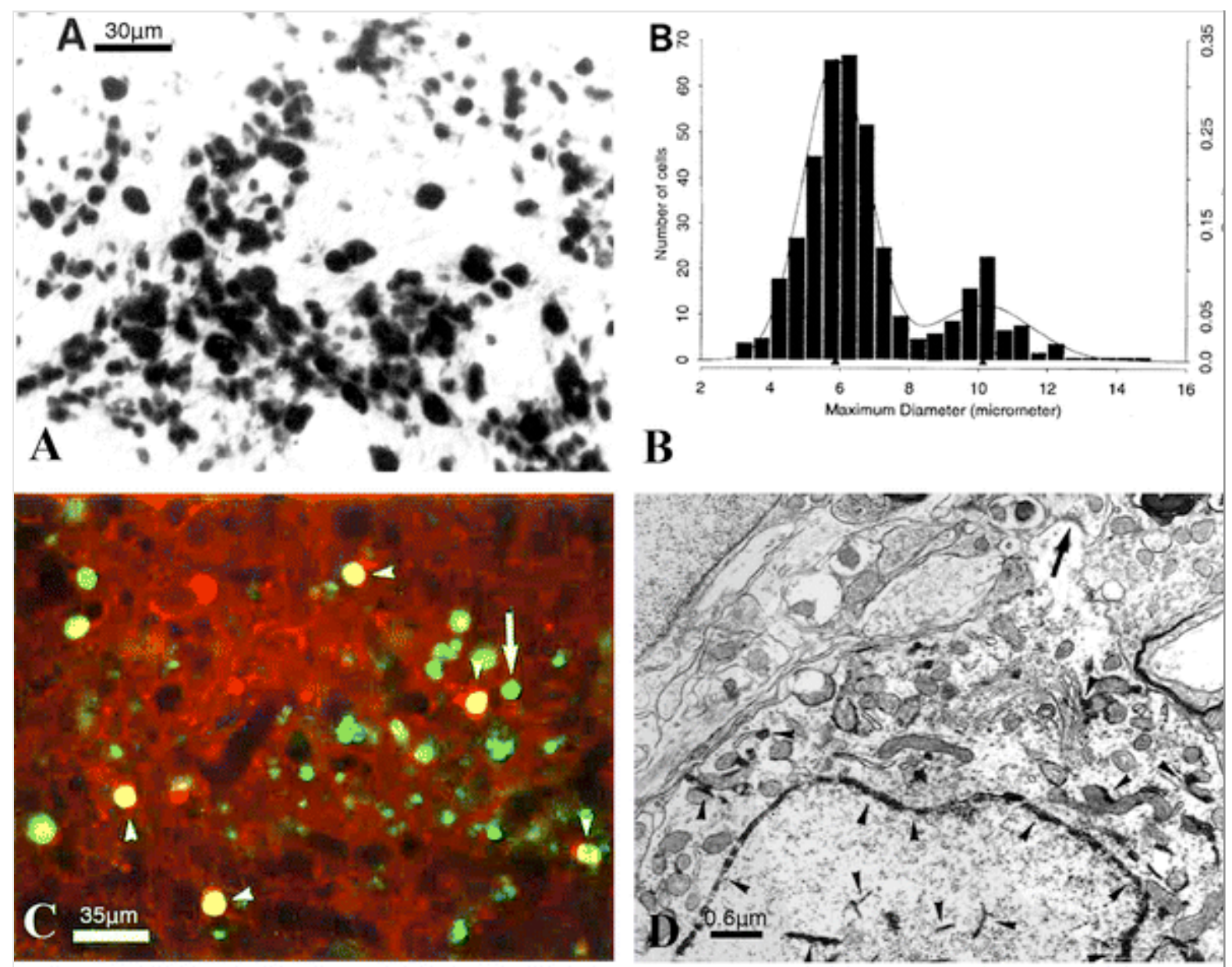

$\mathbf{E}$

8
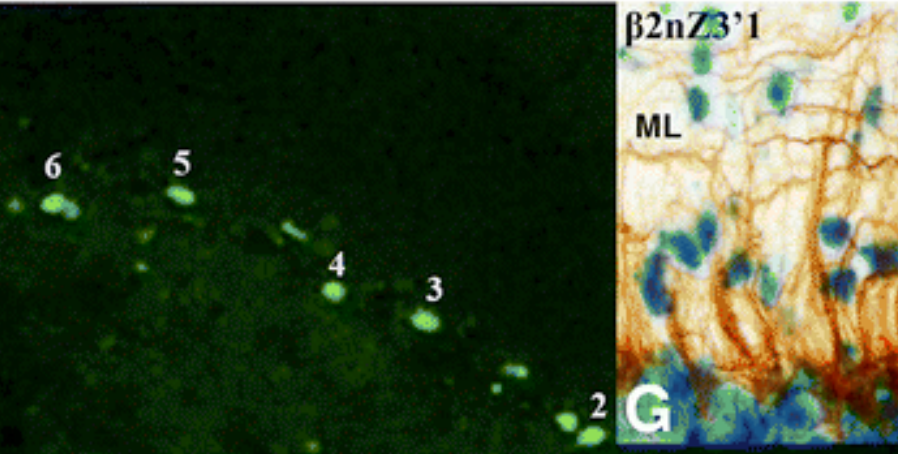

\section{$\beta$-gal 24um}
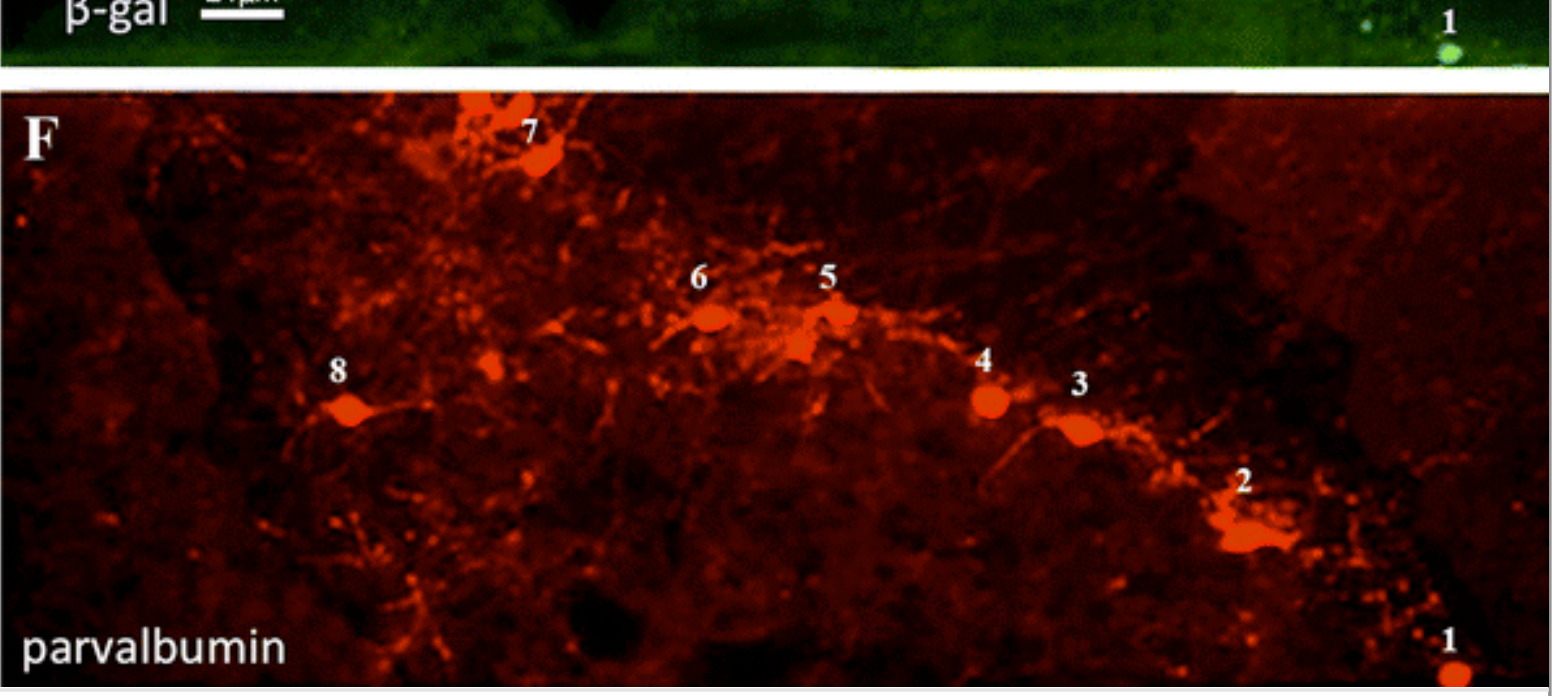
These initial results were used as the bases for Ferdinando Rossi's work in Turin during 2002 to 2012, in collaboration with Barbara Carletti, Ketty Leto, and Chiara Rolando [67-69] in a long series of publications using isochronic or heterochronic transplants grafted in isotopic or heterotopic locations. The first problem to be solved was to determine whether MLIs' progenitors had the ability to generate projection neurons, such as PCs, when grafted into an embryo; the answer is no. Although the final commitment of MLIs is acquired very late in development (see above), in any of the explored situations, postnatal progenitors were capable of generating PCs. This is true not only in our minicerebellar structures generated with mixed grafts of E12 and $\mathrm{P} 4$ cerebella (see above), but mainly in more optimal situations, such as the intracerebellar grafts of postnatal cerebellar progenitors transplanted in utero into embryonic cerebellar anlage [67]. Thus, while grafting of E12 precursors in utero can give rise to all types of cerebellar neurons, transplants of $\mathrm{P} 4$ cerebellar progenitors in the same embryonic conditions only give rise to granule cells and GABAergic interneurons. Although the results obtained from these studies [59, 67-70] did not reveal the complete process of specification of cerebellar GABAergic interneurons, they clearly demonstrated an important difference. Thus, while GABAergic cerebellar projection neurons derive from early specified precursors and acquire their mature phenotypes through cell-autonomous mechanisms, the GABAergic interneurons, in contrast, are produced by a common pool of progenitors and acquire their ultimate phenotype trough microenvironmental cues.

Another problem also partially solved through the heterotopic/heterochronic transplantation approach was to determine the degree of potentiality of the inductive forces of the neurogenic cerebellar PWM microenvironment of the postnatal cerebellum. Is this environment capable of changing the fate of extracerebellar neural progenitors and force them to acquire MLI phenotypes? Or in other words, are MLI progenitors of the postnatal cerebellum capable of acquiring MLI traits in the absence of the neurogenic environment of their PWM? 
The first question was answered by Rossi's team [69] and the second by Jankovski and myself [39]. Rolando et al. [69] compared the developmental potentialities of progenitors from different locations along the neuraxis once exposed to the microenvironment of the postnatal cerebellar PWM. For this purpose, they isolated cells from different regions of the rat central nervous system on a precise time schedule corresponding to the proliferative periods of local interneurons (for instance E15 for the lateral ganglionic eminence, E13 for the dorsal region of the spinal cord, $\mathrm{P} 2$ for the subventricular zone of the lateral ventricle of transgenic rats expressing eGFP under the control of $\beta$-actin promoter) and grafted them into the PWM of the newborn cerebellum (P1). The transplanted rats were analyzed between 2 and 30 days after grafting, and for the study of the phenotypes of the donor cells, the histological sections were double stained with a mouse anti-GFP antibody and either a selective marker of MLIs, parvalbumin [71], or a battery of markers for other neuronal populations, allowing the study of their morphology and some of their neurochemical features. Although the results of these experiments are partially consistent with those of Milosevic et al. [72], the conclusions are quite different. Indeed, despite the fact that the grafted cells were capable of engrafting and differentiating into mature neurons, they never exhibited the unequivocal features of MLIs. In conclusion, the postnatal neurogenic microenvironment of the host cerebellar PWM does not exert enough inductive power on the several classes of donor neuronal precursors studied to transform their original fate into MLIs, which indicates that changing the regional identity of neural progenitors is not an easy task.

Jankovski and Sotelo [39] conducted the second type of experiments aimed at determining whether or not the inductive cues of the cerebellar PWM are indispensable for the specification of GABAergic interneuron's progenitors into adult MLIs. Six to eight-day-old transgenic mice $\beta 2 \mathrm{nZ3} 3^{\prime} 1$ [64], described above for mixed cerebellar transplants, were used as donors. In these mice, the GABAergic interneurons and granule cells (both of late proliferation) are the only cellular populations labeled by the nuclear $\beta$-gal marker (Fig. 4e). Adult OF1 mice were used as hosts. B2nZ3'1 cerebellar progenitors 
were grafted in the subventricular zone (SVZ) at the anterior horn of the lateral ventricle, the origin of the rostral migratory stream (RMS) linking the SVZ to the olfactory bulb (SVZ-OB). To our surprise, we found that a week after transplantation, cerebellar granule cells were absent all along the RMS despite the fact that granule cell progenitors were by far the most numerous progenitors contained in our donor cells. Indeed, after a week in the forebrain, the granule cells had practically disappeared. In those days, we were ignorant of the role of Purkinje cells and their release of sonic hedgehog in the proliferation of granule cell precursors [53]. We attempted to correlate the absence of granule cells with the fact that the RMS was not an optimal migratory substratum for the radial migratory behavior of these neurons and, therefore, they degenerated. Today, the lack of Purkinje cells in the forebrain suffices to explain the observed results. The fate of the grafted cells was studied 6 to 190 days after transplantation using double immunolabeling with anti- $\beta$ gal antibodies, to mark the nucleus and identify grafted cells (Fig. 4e), and anti-parvalbumin, a marker for MLI (Fig. 4f), that is neither expressed in cells of SVZ nor in its vicinity. Another interesting result was that even in the longest surviving cases, the grafted cerebellar neurons never reached the olfactory bulb and remained dispersed for weeks within or around the proximal third of the pathway, maintaining their parvalbumin expression and their stellated shapes. These results conflicted with those obtained in transplantation experiments in which isotopic cells taken from the SVZ of $\beta 2 n Z 3$ ' 1 adult transgenic mice that fortunately also expressed $\beta$-gal activity in their nuclei. In these transplants, 7-day-post grafting, the SVZ cells had already reached the OB (Fig. 7D in [39]), and many of them expressed calretinin but never parvalbumin.

For our present purposes, the main result of our study was that despite the fact that the grafted progenitors proliferated in the RMS and were exposed to local neurogenic signals, they acquired stellate shapes (Fig. 4f) and the majority of them expressed parvalbumin (Fig. 4f), thus maintaining, at least partially, the phenotype of cerebellar MLIs. We explained our results by postulating the following hypothesis: at the end of the last mitosis of the MLIs progenitors, when they already 
expressed Pax2 and had acquired the MLI phenotype, the daughter cells continued their differentiation program, as programed by an internal clock, and quickly began to develop their dendritic trees and to express selective markers such as parvalbumin (in the cerebellum of mice this expression begins around $\mathrm{P} 12$ ). This fast maturation process prevents the migration of neurons with mature features, leaving the RMS, and residing ectopically in the nervous parenchyma in the vicinity of the RMS.

In conclusion, the results mostly obtained by Ferdinando Rossi and his collaborators demonstrated that GABAergic interneurons of the cerebellar cortex derive from a single pool of multipotent progenitors whose fates, production rates, and differentiation schedules are strongly influenced by local cues produced by the microenvironment of the PWM. The latter was considered by Ferdinando Rossi's group [59, 70] as a secondary germinal niche, comparable to the outer subventricular zone in mammalian neocortex. Unfortunately, the molecular and cellular mechanisms governing the interactions between MLI progenitors and PWM remain unknown.

\section{Synaptogenesis}

Purkinje cells, one of the rare examples of projection neurons with inhibitory function, are the only output of the cerebellar cortex. These pivotal elements receive a large majority of their input from two excitatory pathways: a direct one originating from the terminal fields of the axons of inferior olivary neurons, the climbing fibers ("the most powerful and specific excitatory synapse yet discovered in the central nervous system"; [73]), and another, bisynaptically, from mossy fibers through their relay neurons the granule cells (the most numerous neuronal population of the whole CNS and quantitatively speaking the most important input of PCs; [74]). The required inhibitory balance of these two powerful excitatory inputs is mostly provided by MLIs. The understanding of the synaptogenic process between excitatory and inhibitory inputs sustaining the necessary balance between these two types of afferent fibers is, therefore, of great importance. What is already known is that inhibitory GABAergic synapses are a late event in 
PC synaptogenesis since basket cell axons - apparently the first GABAergic fibers to contact PCs [75-78]—-start their synaptogenesis postnatally [ $42,43,76]$, whereas climbing fibers [79, 80], and most probably parallel fibers [81], begin to establish their early synapses on PCs during the last days of the intrauterine life. This fact is again rather paradoxical since in other regions of the CNS, such as the hippocampus, the first neurons to initiate their synaptogenesis are axons belonging to GABAergic neurons, which at that moment exert an excitatory drive [82 ]. In postnatal PCs, from P2 to P6, GABAergic axons also depolarize instead of the expected hyperpolarization [83], allowing the postulation that, as in many other immature neurons [84-87], a concomitant developmental downregulation of chloride-accumulating NKCC1 cotransporter and an upregulation of the chloride-extruding KCC2 cotransporter should occur. However, up till now, NKCC1 expression in PCs takes place too late, by P11, to account for the depolarizing action of GABA.

Using immunohistochemistry with markers of the GABAergic system, either to visualize the expression of its synthetic enzyme the glutamic acid decarboxylase antibodies (GAD), or of the vesicular transporter of inhibitory amino acids (VIAAT) or of GAD65-GFP transgenic mice [44], I have recently studied some of the stages in this synaptogenesis [43]. In the transgenic line, the expression of the transgene is not constant (see above, for PCs the transgene is expressed in practically all of them at birth, but by P5-P7 less than $10 \%$ of PCs are GFP + ). Fortunately, the GFP expression in MLIs is more constant and maintained until at least P21 (the oldest age examined). The first surprise of the study was the abundant presence of VIAATimmunostained fibers in the central white matter of embryonic mouse cerebella, at least in embryos aged from E16 to E18. Very few of these fibers had reached the PCs plate at E16 and thereafter slowly increased in density as seen in E18 cerebella. The origin of these fibers VIAAT+ has not yet been established. For sure, these axons belong neither to PCs nor to MLIs, since they were not double-labeled by calbindin (CaBP, a selective marker for PCs in the cerebellum) or by GFP (endogenously expressed by the cell bodies and neurites of MLIs in the 
used transgenic mice).

As observed by different groups of researches [42, 43, 77], the first GABAergic synapses on PCs occur by P7 and are established on their cell bodies by the descending collaterals of the basket cell axons. Rapidly, numerous descending collaterals originating from nearby basket cells enwrap almost completely the PC perikarya forming the pericellular nests reported by Cajal [12]. These descending basket fibers reach the PC axon initial segment (AIS) by P9, immediately establishing axoaxonic synapses, mostly over the proximal third of the AIS. The pinceaux exhibit their primitive vortex-like arrangements by P12. The exact date in which the AIS and its pinceau are fully matured has not been precisely determined. In rats, where the ultrastructural analysis has been made up to P20, it would be at the end of the first month of extra-uterine life, since at P20 the interbasket fiber septate-like junctions, typical of fully mature pinceaux [88, 89], are still missing. These results strongly suggest that chemical transmission in the AIS precedes the electrical inhibition (see below) and emphasize once more the precocity of the instauration of the chemical transmission in contrast with electrical transmission that, as it was also the case in the inferior olive $[90,91]$, occurs much later.

The understanding of the molecular mechanisms governing the development of pericellular nests and pinceaux formations was clarified 10 years ago by Fabrice Ango working with Josh Huang's team [77]. These researchers revealed the role of an immunoglobulin protein of the L1 family (neurofascin, particularly neurofascin-186, Nfasc) in the orientation of the basket cell axons descending branches towards the PC perikarya and AISs. Moreover, they showed that the cytoskeletal adaptor protein ankyrin-G, confined to the AIS, exerts a high-affinity binding with Nfasc and is responsible of the recruitment of the latter under a gradient form oriented from the AIS to the PC stem dendrite. The gradient is laid down by P7, when the first descending basket fibers reach the Purkinje cell body. These results have been further corroborated in more detail with the use of conditional knock-out mice (Pcp2-Cre; NfascFlox mutants) loosing Nfasc specifically in PCs [92]. 
This selective loss during early development prevented maturation of the AIS and resulted in loss of PC spontaneous activity and failure to maintain depolarization-evoked high-frequency spike firing, along with pinceau disorganization. Thus, Nfasc functions in both PCs and basket neurons, as well as the organization of the pinceau, require the coordinated expression of Nfasc in basket cell axons and PCs [92] in addition of the coordinated expression of ankyrinG in PCs and Nfasc in basket axons [77].

A rather similar approach (GFP BAC transgenic reporter mice) was used by Ango et al. [93] to study molecular mechanisms in the addressing of stellate cell axons to the dendritic domain of PCs. These investigators, analyzing the progressive developmental growth of stellate cell axons, considered that they were guided and organized along PC dendrites as if they followed a scaffold provided by Bergmann glial fibers (BF). Furthermore, they showed that a close homolog of Nfasc, the L1 family immunoglobulin protein Close Homologue of L1 (CHL1), is localized to apical Bergmann glia fibers and stellate cells during the development of stellate axon arbors. More importantly, in mice with CHL1 deletion, stellate axons deviate from BFs and show aberrant branching and orientation. In this situation, synapse formation between aberrant stellate axons and Purkinje dendrites is reduced and cannot be maintained.

These results are of course important but they only reveal part of the developmental mechanisms of the targeting of MLI axons towards their specific domains in PC dendrites, perikarya, and AISs. Indeed, in the studies by Ango et al. [77, 93], the authors neglected anatomical data (reported above in the section devoted to history) already described by Cajal in his pioneer studies (Fig. 1d), clearly showing that the axons of the basket cells branch out not only numerous descendant collaterals towards the PC perikarya, but also short ascending collaterals that are targeted towards the proximal dendritic compartment of PC dendrites. Cajal has also drawn stellate cells in the middle of the molecular layer with axons whose collaterals descent to the level of PC perikaya, contributing to the pinceaux formations (Fig. 1c). It is obvious that the 
described molecular mechanism by Ango et al. [77, 93] cannot explain the targeting of all MLI axonic branches. Indeed, in a more recent paper [94], the same group of investigators has shown that guiding molecules expressed by PCs, in this case SEMA3A via its receptor Neuropilin-1, is also required for the normal branching of the terminal segments of the basket fibers. Finally, it is important to mention the anatomical relationships observed in adult cerebella between climbing fibers and basket cell axons not only in Golgi impregnated preparations but mainly with electron microscopy (Fig. 5f), as reported by Chan-Palay and Palay [95]. For these authors, climbing fibers and basket cell axons run along parallel to each other as they ascend over the surface of the PC dendrites towards the outermost regions of the molecular layer. There it is possible to observe thin astrocytic processes that separate the two axons from each other, even though areas of direct apposition do exist, some of them of several microns long. Both fibers form especially elaborate intertwined festoons at the branching points of the major dendrites, where synaptic contacts are frequent. This privileged anatomical situation could have a functional meaning in the regulation of PC firing rates, since it is at these dendritic branching points that the calcium dendritic spikes are believed to originate [96].

\section{Fig. 5}

Electron micrographs of the molecular layer of mature rat cerebellar cortex. These electron micrographs exemplify the divers types of common $(\mathbf{c}-\mathbf{f})$ and rare $(\mathbf{a}, \mathbf{b})$ synaptic connections established by MLI axons on PCs and GABAergic interneurons. From (a to d), the GABAergic nature of the presynaptic boutons is corroborated by their GABA-immunogold (b to d) or glutamic acid decarboxylase (GAD) HRP-immunolabeling (a). a and $\mathbf{b}$ inhibitory axons of the molecular layer synapsing on PC dendritic spines (S). c Basket cell axon (BF) establishing a synaptic contact on a PC soma identified by the presence of the hypolemmal cistern (asterisks). d Synaptic investment of a cell body of a MLI composed by three axon terminals, two belonging to parallel fibers (PF) and the third one to the axon terminal of another MLI as testified by its GABA immunogold labeling. The PFs establish asymmetrical synapse (crossed arrows) whereas the synaptic complex of the third bouton is of the symmetrical type (arrow) like inhibitory 
synapses. e A long basket cell axon (arrow) with light axoplasm containing abundant neurofilaments gives off an elongated axon terminal (BF), containing a long mitochondrion and flattened vesicles; the latter is establishing a long synaptic complex (arrowhead) with a PC perikaryon, in a young rat aged of 15-day (P15). f A climbing fiber axon terminal (CF) is synapsing on a PC dendritic spine (S). Note the nearby presence of another axon terminal with a less electron dense axoplam and flattened instead of rounded synaptic vesicles. The latter most probably belongs to an ascending collateral of a basket cell axon (BF) synapsing on the shaft of a large PC dendritic profile ( $\mathrm{PC}$ den). The hypolemmal cistern is marked by asterisks. (a and b) scale bar in (a). (c and d) scale bar in (c). (e and f) scale bar in (e) 

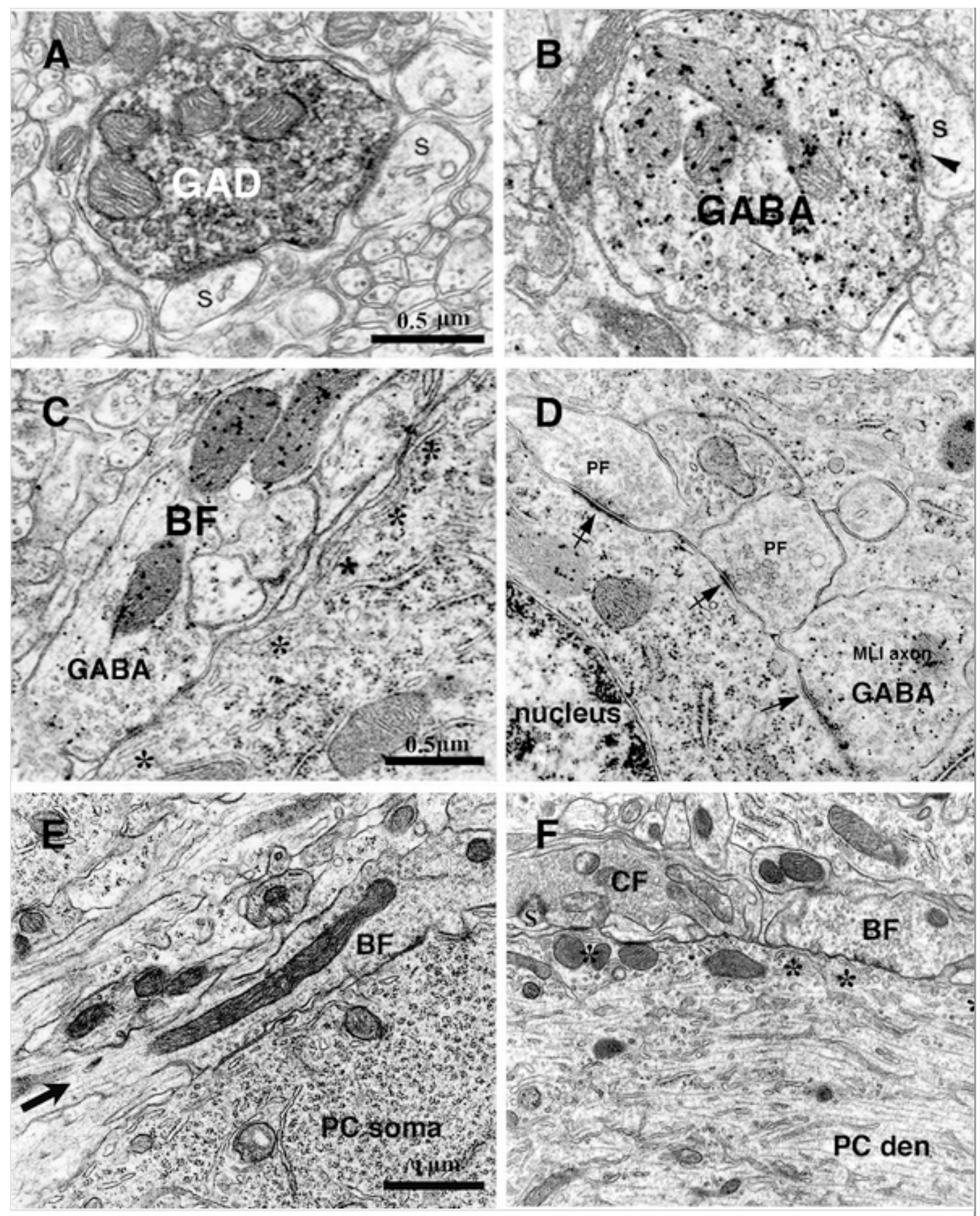

An interesting aspect of the development of these MLI/PC synapses, revealed a few years ago [97], involves some differences between synapses on PC perikarya and those on PC dendrites. The authors analyzed the clustering of GABA-A receptors and of the scaffolding molecule gephyrin. In dendritic synapses, both proteins co-aggregate with a punctate pattern in those points of the postsynaptic membrane 
apposed to VIAAT immunostained boutons. In perisomatic synapses, the colocalization GABA-A/gephyrin is visible from P9-P7, when the synaptogenesis between MLI axons and PCs starts [43, 77]. In contrast, the presence of gephyrin clusters in peridendritic synapses is transient and gradually disappears. This gephyrin loss was accompanied by an important decrease in the size of the GABA-A clusters and, therefore, in the length of the synaptic complexes (active zones and postsynaptic differentiations). Many years ago, Larramendi [98] reported a similar waning in the maturing synapses between basket cell axons and PC perikarya, now we know one of the molecular reasons for this decline, emphasizing the role of the scaffolding protein gephyrin in the initial assembly of inhibitory postsynaptic receptor sites.

\section{New Data on the Adult Inhibitory Circuit of Molecular Layer Interneurons}

It is customary for many cerebellum specialists, when commenting on the adult synaptic circuitry of the cerebellar cortex, to follow the main principles of the neuronal synaptic interactions first established by Cajal and to add that little has changed since then. The basic principles of the cortical circuit were carefully and precisely indicated in the semi-schematic drawing published by Cajal in his book "Nouvelles Idées sur la Structure du Système Nerveux chez l'Homme et chez les Vertébrés" [99]. The truth of the interneuronal synaptic connections postulated by Cajal became apparent after electron microscopic studies carried out between 1955 and 1965 by Palay, Gray, Hamori, and others (see more references in [74]), and the electrophysiological analyses of Eccles, Llinás, and Sasaki [15, 100, 101], which corroborated and expanded Cajal's assumptions. Nevertheless, as recently recalled [43, $102]$, neuroscience has made extraordinary advances in the last 50 years, and our knowledge of the cerebellum anatomy and function has been broadly expanded. A few of the more notable advances are the discovery of the monoaminergic paracrine innervation, especially by noradrenaline and serotonin [103-107], the finding of new interneurons, starting a few years after Cajal by the discovery of the Lugaro cells [108] and ending with the finding of unipolar brush cells, 
a glutamatergic kind of interneuron only located in the granule cell layer of ventral cerebellar lobules [1], and the occurrence of electrical synapses between GABAergic interneurons of the mammalian cerebellar cortex [89]. Finally and most importantly, the discovery of new and unexpected projections was revealed by the use of retrograde transneuronal transport of herpes simplex virus type 1 (HSV1) [109]. These researchers labeled second-order neurons, thereby identifying subcortical neurons that project via the thalamus to area 46 of the primate prefrontal cortex. Among the neurons retrogradely labeled, many of them were located in the cerebellar dentate nucleus, providing for the first time anatomical evidence of the existence of a cerebellar link with association areas of the cerebral cortex. Since the area 46 of the prefrontal cortex is known to be involved in spatial working memory, these anatomical data have opened a new and important line of research suggesting that the cerebellum is not only a center for motor control but is also involved in higher cognitive function and affect (see in [110]). The cerebellum has, therefore, acquired an unexpected psychiatric importance.

(a) Afferent and efferent fibers on molecular layer interneurons

The relatively simple structure of the cerebellar cortex and the ability to discern at the electron microscopic level excitatory from inhibitory chemical synapses have provided neurocytologists with the opportunity to analyze the synaptic connections of MLIs, completing the circuitry hypothesized by Cajal [99].

Ultrastructural quantitative studies have shown that there are quantitative, not qualitative, differences in MLIs afferents in relation to their location either in the lower, middle, or upper molecular layer. Those in the deepest zones receive, in addition to a large amount of synapses from parallel fibers and some rare boutons from climbing fibers (the Scheibel collaterals) [111], inhibitory inputs mainly from PC axon collaterals [112].

Whereas, those in the deeper third of the molecular layer (the proper location of the basket cells) receive upon both their cell bodies and dendrites mostly parallel fiber synapses and lesser amounts of MLI axon terminals and Purkinje axon collaterals. 
Finally, the superficial ones, the stellate cells, receive only parallel fiber and a few stellate axon terminals [113].

To this, so called classical synaptology of MLI interneurons, we need to add more recent discoveries mainly by Lainé and Axelrad [114] who with the use of the Golgi impregnation, and the Golgi gold toning for ultrastructural analysis was able to show that the axons of the Lugaro and globular cells (most probably a subclass of Lugaro neurons [115]) ascend into the molecular layer and establish synaptic contacts with at least the lower somata and dendrites of the deep MLIs. These results have been recently corroborated by the group of Jean-Marc Fritschy that, with the transgenic mouse line "GlyT2 gene promoter-driven GFP" mentioned above [43], were able to identify axons belonging to GABAergic Lugaro and globular cells of the upper granular layer (GlyT2 + GAD + mGluR2 cells) entering the molecular layer and establishing synaptic contacts with parvalbumin positive interneurons, as well as Golgi cell dendrites [43]. These results are of great interest because Lugaro and globular cells are also heavily innervated by PC axon collaterals and, therefore, may form a feedback loop controlling PCs activity via MLIs.

With reference to the afferent inputs of parallel fibers to neuronal elements in the molecular layer, it is important to remember the importance that GluD1 (one of the two members of the $\delta$ subfamily of ionotropic glutamate receptors, [116]) has in the formation and maintenance of the synapses between parallel fibers and MLIs, as recently shown by Kohtarou Konno and collaborators [117]. These authors have not only demonstrated the presence of GluD1 on the postsynaptic membrane of MLIs' receiving parallel fibers synapses, but also that its deletion in GluD1 KO mice lead to a significant decrease in the number of these types of synapses. Based on these results, Konno et al. [117] propose that GluD1 works in concert with GluD2 (a second member of the $\delta$ subfamily of ionotropic glutamate receptors, identified as an essential molecule for the building up of synapses 
between distal spines of PC dendrites and parallel fibers) [118, 119 ], in the construction of cerebellar synaptic wiring, and since parallel fiber/MLI synapses are essential for the feedforward inhibition from granule cell to PCs the deletion of GluD1 should result in an important decrease of this inhibition.

With regard to the efferent connections of MLIs, it has been concluded that these interneurons establish synaptic connections with all neuronal elements encountered in the molecular layer, mainly somata and shafts of the proximal dendritic compartments of the PCs, but also with somata and dendrites of basket and stellate cells, but only with the dendrites of Golgi cells (their cellular bodies are in the granule cell layer) [74]. One problem with this type of cytological analysis is the precise identification of pre- and postsynaptic elements involved in each synapse. The numerous previous light microscopic studies in Golgi impregnated material clearly indicated that the inhibitory axons present in the molecular layer belonged solely to MLIs, even though its deepest region also contained recurrent collaterals of PC axons. At the ultrastructural level, all these inhibitory axon terminals contained flattened vesicles, as well as other reliable features that may aid in their identification. For example, recurrent collaterals of PC axons are myelinated and contain a semi-dense axoplasmic matrix, whereas basket and stellate cell axons are amyelinated and their axoplasmic matrix is not electron dense [74]. Therefore, it is often possible to identify MLI axon terminals by their morphological features, and even better by the labeling with anti-GABA or anti-glutamic acid decarboxylase (GAD) antibodies. With these tools in hand, it was possible to explore the partners involved in MLI efferent connections and to corroborate their participation to the synaptic investment of other MLIs (Fig. 5d) and of the PCs. Remarkably, although the vast majority of MLI's synaptic boutons establish synaptic contacts with the soma of PCs (Fig. 5c, e), and that, as reported above, the ascending collaterals of the axons of the basket cells run for long pathways over the surface of PC dendrites in parallel with the 
climbing fibers, which are often found in close proximity (Fig. 5f), these axons also rarely synapse on PC dendritic distal spines (Fig. 5a, b), the unequivocal targets for the myriads of parallel fibers present in the molecular layer.

The problem is more complicate and the solution harder to find with the molecular layer dendritic profiles. Indeed, with exception of PC dendrites that carries an intrinsic cytological identifier, the hypolemmal cisterna (Fig. 5c, asterisks) specialized part of the smooth endoplasmic reticulum closely underling the plasmalemma [120] that makes these dendrites recognizable, the identification of the other classes of dendrites would require immunomarkers. Unfortunately, for the time being there are no selective markers to distinguish basket from stellate dendrites. In any case, the almost constant presence of MLI axon terminals in large dendritic profiles not belonging to PCs has prompted some investigators to speculate that MLIs also synapse on Golgi cell dendrites [74]. Similarly, only based upon indirect physiological evidence, it has been considered that MLIs inhibit Golgi cells in the same manner as PCs [121]. This deeply rooted conclusion seems to be hypothetical, since only based on the fact that as the chemical synaptic inhibition between Golgi cells has not been found easily, the most suitable candidates to produce GABAergic inhibition in Golgi cells were the MLIs [122-124]. Nevertheless, a few years ago, the problem of the Golgi cells contribution to local cerebellar processing was approached by analyzing how their activity is regulated by synaptic inhibition [120]. In contrast to previous works, Hull and Regehr [125] showed that MLIs are not at all responsible for the GABAergic inhibition of Golgi cells and that, with the exception of a limited inhibition transiting through Lugaro cells with the help of serotonin [126], other Golgi cells were primarily responsible for the inhibition. These new results somewhat changed our vision of the inhibitory wiring diagram of the cerebellar cortex.

(b) Electrical inhibition of Purkinje cells by the pinceaux of MLI 
axons

One of the most unusual synaptic organizations, probably unique in the mammalian CNS, is the pinceau formation. Historically speaking, it was crucial for Cajal. The morphological analysis of these strange arrangements convinced him that the "diffuse network" proclaimed by Golgi did not exist and that neurons communicated by contact, paving the way to a new era in the history of neuroscience (see above). From early electron microscopic studies $[74,127,128]$, the pinceau is described as a vortex-like arrangement of the distal portions of the pericellular basket fibers around central thin AIS of PCs. These long fibers descend from the basal pole of the PC perikaryon converging towards the first heminode of its axon. The MLI descending fibers are intermingled with thin astrocytic processes, the whole making a kind of palisade around the AIS. The astrocytic processes cover the vast majority of the AIS membrane, leaving little room for direct appositions between the membrane of the basket axons and the membrane of the PC AIS. In addition, despite their privileged location, the basket cell axons forming the pinceau are not filled with synaptic vesicles, and very rare active zones are established with the AIS. In our paper of 1968 [128], we concluded that in the 60 sections of the different PCs whose AISs have been studied, only in one case an axo-axonic synapse between the basket fiber and the AIS was observed, in contrast to what happened in the AISs of pyramidal cells in the cerebral cortex, where almost in every section an attached synaptic bouton was present. This study was nicely complemented by a quantitative analysis of synaptic complexes using threedimensional reconstruction of pinceaux in electron microscopy through serial sections. In this study, Somogyi and Hamori [129] concluded that axo-axonic synapses were rare (2.9 and 3.5 per AIS in the rat and cat, respectively).

A later immunohistochemical study examining the expression of molecules involved in GABAergic signaling (GAD, VIAAT, 
GABAA-R $\boldsymbol{\alpha} 1$ receptor, and others) revealed that GAD and VIAAT immunogold labeling was five times lower in the pinceaux when compared with perisomatic basket cell terminals and no accumulation toward the AIS was detected [130]. This apparent paradox, overcrowding of axons and lack of molecules and organelles specialized in the release of the inhibitory neurotransmitter, both in the optimal region to exert strong inhibition, could be explained with a detailed analysis of the ultrastructure of the pinceaux, particularly of intercellular junctions. Indeed, years ago, in two papers that appeared in separated issues of the same journal, Stephen Gobel [88] and ours [89] reported the occurrence of a new type of junction which resembled the septate junctions of invertebrate epithelia and that we called "septate-like junctions". In these junctions, all along the length of the contact, the intercellular cleft contained periodic electron opaque densities, disposed perpendicular to both plasma membranes attached to their outer leaflets and almost regularly spaced about $14 \mathrm{~nm}$ apart. These densities bridging and occluding the extracellular space between apposed basket fibers or basket fibers and thin astrocytic processes were not prismatic like in invertebrates septate junctions and often exhibited a Greek-cross shape.

The pinceau is also a favored location for voltage-gated potassium channels $(\mathrm{Kv}) . \mathrm{Kv} 1.1$ and Kv1.2 were the first to be encountered in association with the septate-like junctions and the protein SAP90, also known as PSD95 [131]. Some years later, Kv3.2 and aquaporin-4 were added to the list of channels present at the pinceau [132]. The association of these channels with septate-like junctions, and the absence of Nav channels (the latter are only present in the membrane of the AIS) [131], can be considered in favor to the hypothesis we formulated in 1972. Indeed, by comparison with what was already known for the electrical inhibition in the axon cap of Mauthner cells [133], we proposed that the septate-like junction could function as a highly resistive element channeling extracellular current flow, thus 
serving as a means of generating a highly anisotropic volume conduction; in other words, it would act as an anodal blocking device provoking the electrical inhibition of the PC. Some years later, Antoine Triller and Henri Korn [134] reported the occurrence of similar septate-like junctions, also occluding the extracellular space, between astrocytic processes in the Mauthner cell axon cap, and a few months later in collaboration with Herbert Axelrad [135], they published the first electrophysiological analysis of the pinceau in adult rat cerebellum suggesting a functional similarity between the electrical inhibition of the Mauthner cell axon cap [133] and the mammalian pinceau around the PC AIS. Even though the main conclusion, the inhibition at the pinceau formation is not chemical but electrical, has been corroborated, the mechanism proposed by Korn and Axelrad [135] was incorrect. In fact, in a very recent study, Blot and Barbour [136, 137] reported that the data of Korn and Axelrad were unrelated with the operation of the pinceau and were the result of a signal arising from the massive stimulation of parallel fibers used by these authors. For Blot and Babour [137], "the pinceau mediates ephaptic inhibition of Purkinje cell firing at the site of spike initiation. The reduction of firing rate was synchronous with the presynaptic action potential, eliminating a synaptic delay and allowing granule cells to inhibit Purkinje cells without a preceding phase of excitation. Axon-axon ephaptic intercellular signaling can therefore mediate near-instantaneous feedforward and lateral inhibition."

(c) Electrical synapses between molecular layer interneurons

The ultrastructural and microphysiological studies on fast- and short-term interactions between neurons have revealed the complexity of the mechanisms operating in neuronal communication. In the last 50 years, the existence of electrical interactions - in addition to chemical synapses - between neurons of the mammalian central nervous system has been established beyond doubt $[138,139]$. Regarding the morphological 
requirements of electrical transmission, one must keep in mind that neurons are independent units almost completely isolated from each other by glial processes. At sites where two or more neuronal elements are directly apposed, they are still separated from each other by their own plasmalemmas and by an extracellular cleft $15-30 \mathrm{~nm}$ in width. The electrical resistance of the membranes and of the cleft is great enough to prevent significant electrotonic coupling between cells. Therefore, electrical interactions must necessarily occur at specific locations on the neuronal membrane, which could constitute low resistance pathways. Combined electrophysiological and ultrastructural studies have clearly shown that the morphological correlate of low resistance pathways corresponds to a particular class of membrane junction named "gap junction" [140]. Gap junctions between neurons share all their internal features with those commonly studied between non-excitable cells. In material stained "en bloc" with uranyl acetate before Araldite embedding to bring out the unit membrane morphology, neuronal gap junctions lie on small zones or plaques where the extracellular space narrows considerably to a minute gap of approximately $2 \mathrm{~nm}$ in thickness, and the two apposed membranes lie parallel, exhibiting a heptalaminar configuration, resulting from the closeness of the junctional membranes. The overall width of these junctions was about 14 to $15 \mathrm{~nm}$. Importantly, a cytoplasmic semi-dense band undercoats the whole length of the inner surfaces of the junctional plasmalemmas. Neither the "labile appositions" nor the true gap junctions linking astrocytes or oligodendrocytes were provided with bilateral undercoating.

Gap junctions are composed of aggregations of membrane channels, called connexons, joined with similar connexons in adjacent cells to form a dimer that establish an intercellular pathway for the diffusion of ions and small-molecular weight molecules, up to a maximum of 1000 Daltons. The resulting intercellular communication is unique in that adjacent cells exchange cytoplasmic molecules directly, with no secretion into the 
extracellular space $[141,142]$. Due to the large size of the intercellular channels formed by pairs of connexons, the exchange of molecules between cells is not specific but remains regulated [143-146]. The connexon hemi-channels on each cell membrane delimit a tiny funneling tunnel that is not passive but, on the contrary, has a proper chemical regulation controlled by intracellular (second messengers, $\mathrm{Ca} 2+, \mathrm{pH}$ ) and extracellular signals (mainly neurotransmitters and nucleotides), which allows its opening and closure accordingly to a specific pharmacology. Members of a large family of proteins called connexins form the connexons. Six molecules of connexins bridge the plasmalemma of the two linked neurons, at least 20 connexin genes code for gap junction proteins in mice and humans. In rodents, the gap junctions establishing electrical synapses are mostly composed of connexin 36 , although connexin 45 or connexin 57 proteins can also contribute to electrical synapses depending on the type of neuron [147].

Forty-two years ago, in collaboration with Rodolfo Llinas [89], we were the first to describe the presence of gap junctions between MLI in the cat and rat cerebella. The gap-junctional plates were spread on the molecular layer, particularly in its deeper half although they were also present in the upper half and seemed to affect to all or at least the vast majority of MLIs. They exhibited similar features than those described above (14-15 nm wide and bilateral undercoating) and were formed by the plasmalemmas of two neuronal profiles belonging to distinct neurons. Most frequently, the two profiles linked by a gap junction were medium-sized dendrites, less often a perikaryon and a dendrite and more rarely two perikarya. In our original paper, we postulated that not only MLI dendrites were linked by gap junctions, but also Golgi cell dendrites between them, and even Golgi and MLI dendrites. Indeed, some of the observed dendritic profiles lying deep in the molecular layer, measuring between 2.5 to $3 \mu \mathrm{m}$ in thickness, devoid of hypolemmal cistern, deficient in spines, and establishing synaptic complexes with parallel fiber varicosities on 
their smooth surface were considered to belong to Golgi cells. The same criticism raised in the section on "Afferent and efferent fibers on molecular layer interneurons" can be used here to weaken the indirect argument used in the identification of these dendrites. Therefore, at present, there is no direct morphological evidence that MLIs are coupled to Golgi cell through gap junctions, although there is no doubt that gap junctions also link Golgi cells between them. Therefore, the interneuronal gap junctions of the cerebellar cortex seem to be only established between homologous classes of neurons.

In a study of the ultrastructural features of the cerebellar cortex of the mutant mouse nervous ( $n r / n r)$ more than 1 year old, we were surprised to see that the membrane junctions between basket cell fibers underlying electrical synapses and ephaptic interactions were maintained for months after the degeneration of PCs, the target of these fibers [148]. Nervous is an autosomal recessive mutation that causes postnatal death of about $90 \%$ of Purkinje cells in the lateral hemispheres and of more than $50 \%$ of them in the vermis. The vast majority of PC death takes place during the first 2 months after birth. In this cerebellum, as in many other examples of death of post-mature PCs, pericellular nests remain even months after the disappearance of their targets, creating what neuropathologists named "empty basket" (Fig. 6d). Gap junctions (Fig. 6a, b), and septate-like junctions (Fig. 6a, c), linking basket fiber membranes do occur at least up to mice aged 420 days. The occurrence of these junctions in "empty baskets" clearly indicates that the electrical inhibition between basket fibers and PCs is not required for their maintenance.

\section{Fig. 6}

Electron micrographs illustrating that the morphological substrata for ephaptic interactions did not disappear in the "empty baskets" of the aged nervous mouse cerebellum. a In this mutation the majority of the PCs degenerate between P23 and P60, but their afferent synaptic fibers, particularly basket cell axons (BF) remain for months (340 days in this case) in the absence of their postsynaptic 
targets. The micrograph shows a bundle of five BFs with broad areas of their membranes directly apposed. In precise regions of these appositions, two types of membrane junctions are found: a gap junction (framed area) and a septate-like junction (between arrows). A higher magnification of this seven-layered junction is presented in (b). c High magnification of a septate-like junction established between two basket fibers. All along the length of the contact, the intercellular cleft contains periodic electron opaque densities, disposed perpendicular to both plasma membranes. d Light microscopy of silver impregnated basket fibers in a 232-day-old nervous mouse illustrating "empty baskets". The numbers over the scale bar indicate the microns. Figures taken from the paper of Sotelo and Triller (1979)

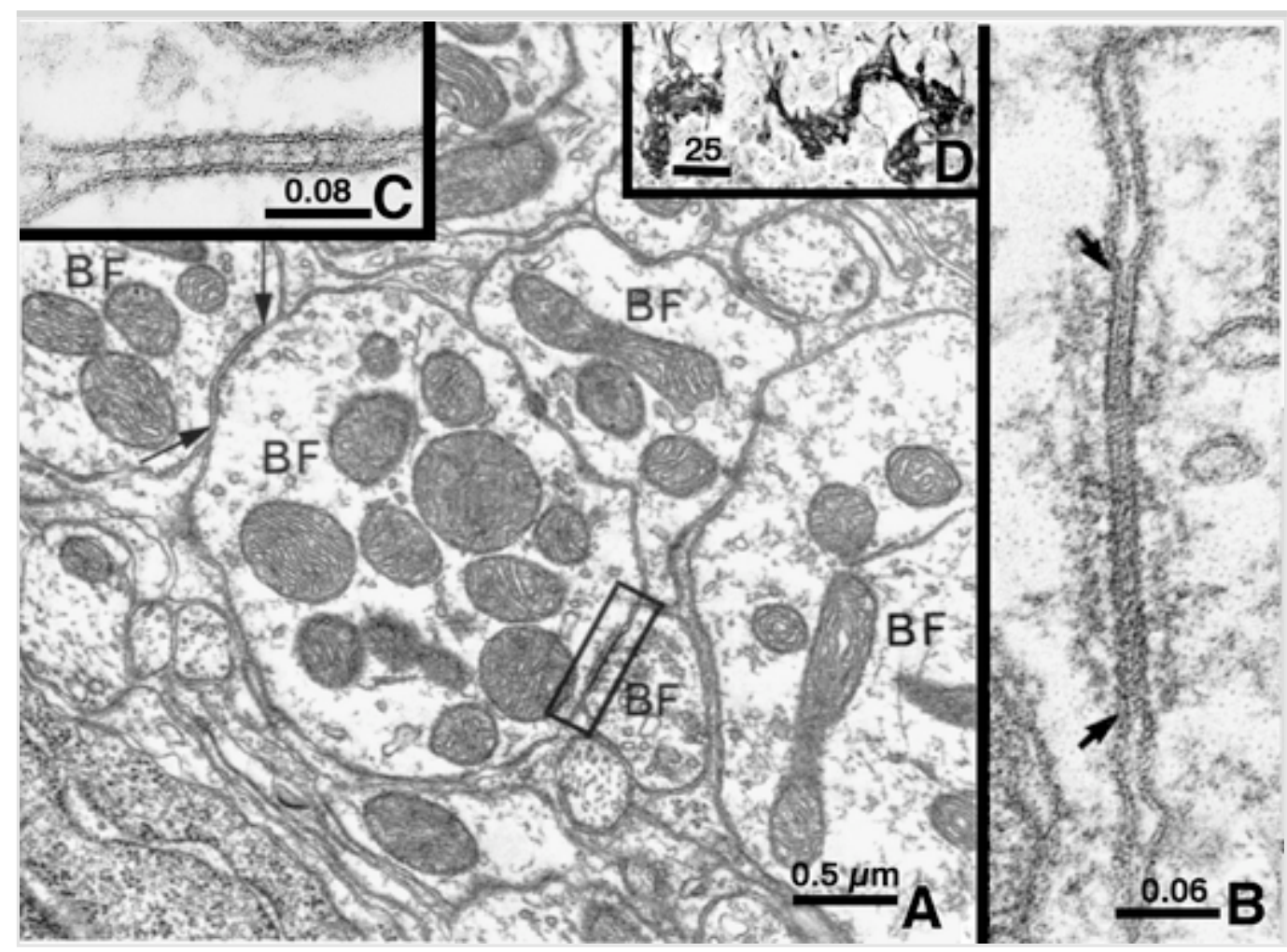

Double immunohistochemical labeling carried out by Belluardo et al. [149] with anti-parvalbumin antibodies to identify MLIs and connexin 36 (Cx36) antibodies showed that the most frequent form of connexin encountered among neurons was also present in the electrical synapses linking MLIs. Moreover, Cx45 was also observed in almost all the MLIs, both during early postnatal 
development and in adulthood [150]. It is of interest to note that the latter investigators also studied the ultrastructure of the inter-MLI gap junctions in mice with deletion of the $\mathrm{Cx} 45$ gene and that, in contrast with knockout mice of $\mathrm{Cx} 36$, the gap junctions exhibited normal morphology. These observations suggest that $\mathrm{Cx} 45$ was not indispensable for the formation of ML-interneuronal gap junctions.

Finally, Pepe Alcami and Alain Marty [151], using in vitro slices with dual recording of electrical synapses, have determined through the study of capacity currents obtained under voltage clamp in MLIs of juvenile rodents (P10 to P14 rats and mice), the number of cells directly connected to a reference neuron and the extent of charge redistribution in the network. They reached the conclusion that the number of direct neighbors is $\sim 4$ for rat basket cells and only $\sim 1$ for rat stellate cells and, therefore, that in juvenile rodents, electrical communication is stronger among basket cells than among stellate cells. Rela and Szczupak [152] postulated that electrical synapses could be important in redefining neuronal compartments that, by linking together distinct neuronal populations, might establish functional units. This hypothesis has been recently tested in an interesting paper of the group of George Augustine [153]. These investigators used in vitro cerebellar slices taken from transgenic mice expressing channelrhodopsin-2 exclusively in MLIs to reveal the spatial organization of MLI circuits through optogenetic mapping. Their results corroborate, first, that several MLIs (seven in their experiments converge upon a single PC; see in [74]). More importantly, the blockage of gap junctional channels with one of the three specific blockers tested, meclofenamic acid (MFA $200 \mu \mathrm{M}$ ), carbenoxolone (CBX $200 \mu \mathrm{M}$ ), and mefloquine (MFQ $50 \mu \mathrm{M}$ ), reduces the amount of convergence but only in sagittal slices, not in coronal ones, indicating a sagittal bias in electrical coupling between interneurons. These results emphasize the important role of electrotonic coupling between MLIs in the spatial coordination of these interneurons, guaranteeing a precise pattern of synaptic inhibition on PCs in 
response to distinct patterns of parallel fiber input.

In conclusion, the recent additional knowledge on the inhibitory circuits of the cortex of the cerebellum, without revolutionizing completely the circuitry envisioned by Cajal, has opened new important directions of analyzing the function of the cerebellar cortex. Instead of only considering the role of single neurons, now more interesting models can be imagined by analyzing the effect of inhibitory interneuronal assemblies on PCs, since both the number and the geometry of activated MLI assemblies could modulate not only the dynamic of the coupling strength, but also the spatial coordination of these GABAergic interneurons [153].

\section{Acknowledgments}

This work was supported by Grant BFU2013-48230 from Ministerio de Economía y Competitividad. Spain.

\section{Conflict of Interest}

I, Constantino Sotelo, hereby certify that I have neither financial nor personal relationships that might bias this work (e.g., consultancies, stock ownership, equity interests, and patent-licensing arrangements).

\section{References}

1. Mugnaini E, Floris A. The unipolar brush cell: a neglected neuron of the mammalian cerebellar cortex. J Comp Neurol. 1994;339:174-80.

2. Cajal SR. Textura del sistema nervioso del hombre y de los vertebrados, vol. 2. Madrid: Imprenta y Librería de Nicolas Moya; 1904.

3. Bellonci G. Contribuzione all'istologia del cervelletto. Approvata per la stampa negli atti dell'Accademia nella seduta del 6 marzo 1881. p. 49. 
4. Denissenko G. Zur Frage über den Bau der Kleinhirnrinde bei verschiedenen Klassen von Wirbelthieren. Arch Mikrosk Anat. 1877;14:203-42.

5. Huguenin G. Allgemeine Pathologie der Krankheiten des Nervensystems. Ein Lehrbuch für Aertze und Studirende. 1 Theil. Anatomische Einleitung. Zürich: Ziircher \& Furrer; 1873. p. 296.

6. Meynert T. Vom Gehirne der Saugetiere. In: Stricker S, editor. Handbuch der Lehre von den Geweben des Menschen und der Thiere. Leipzig: Englemann; 1871-1872. Vol.2, pp.694-808.

Translated by Henry Power as: The brain of mammals. In: Stricker S. ed. Manual of Human and Comparative Histology. London: The New Sydenham Society. vol. 2. p. 367-537.

7. Schwalbe GA. Lehrbuch der Neurologie. In: Hoffmann CEE, editor. Lehrbuch der Anatomie des Menschen. Erlangen: Von Eduard Besold; 1881. p. 287-1026.

8. Golgi C. Sulla fina anatomia del cervelletto umano. Arch Ital Mal Nervose. 1874;11:90-107.

9. Golgi C. Sulla fine anatomia degli organi centrali del sistema nervoso. Reggio Emilia: Tipografia S. Calderini e Figlio; 1885.

10. Fusari R. Sull'origine delle fibre nervose nello strato molecolare delle circonvoluzioni cerebellari dell'omo. Atti R Accad Sci Torino. 1883;19:47-51.

11. Cajal SR. Estructura de los centros neviosos de las aves. Rev Trim Histol Normal Patológica. 1888;1:1-10.

12. Cajal SR. Sobre las fibras nerviosas de la capa molecular del cerebelo. Rev Trim Histol Norm Patológica. 1888;2:33-41.

13. Cajal SR. Estructura del cerebelo. Gaz Méd Catalana. 1888;11(267):449-57. 
14. Andersen P, Eccles JC, Voorhoeve PE. Inhibitory synapses on somas of Purkinje cells in the cerebellum. Nature. 1963;199:655-6.

15. Eccles JC, Llinas R, Sasaki K. The inhibitory interneurons within the cerebellar cortex. Exp Brain Res. 1966;1(1):1-16.

16. Obata K, Ito M, Ochi R, Sato N. Pharmacological properties of the postsynaptic inhibition by Purkinje cell axons and the action of $\gamma$-aminobutyric acid on Deiters neurons. Exp Brain Res. 1967;4:43-57.

17. Palade GE, Palay SL. Electron microscope observations of interneuronal and neuromuscular synapses. Anat Rec 1954; (Oral presentation) 118: 335. Cited in Palay SL. Synapses in the central nervous system. J Biophys Biochem Cytol. 1956;2(4 Suppl):193-202.

AQ2

18. Cajal SR. Sur l'origine et la direction des prolongations nerveuses de la couche moléculaire du cervelet. Int Monatsschr Anat Physiol. 1889;6:158-74.

19. Mugnaini E. Ultrastructural studies on the cerebellar histogenesis. II.Maturation of nerve cell populations and establishment of connections in the cerebellar cortex of the chick. In: Llinás R, editor. Neurobiology of Cerebellar Evolution and Development. Chicago: AMA-ERF Institute for Biomedical Research; 1969. p. 749-82.

20. Mugnaini E. The histology and cytology of the cerebellar cotex. In: Larsell O, Jansen J, editors. The Comparative Anatomy and Histology of the Cerebellum: the Human Cerebellum, Cerebellar Connections and Cerebellar Cortex. Minneapolis: University of Minnesota Press; 1972. p. 201-65.

21. Paula-Barbosa MM, Tavares MA, Ruela M, Barroca H. The distribution of stellate cell descending axons in the rat cerebellum: a 
Golgi and combined Golgi-electron microscopical study. J Anat. 1983;137:757-64.

22. Sultan F, Bower JM. Quantitative Golgi study of the rat cerebellar molecular layer interneurons using principal component analysis. J Comp Neurol. 1998;393:353-73.

23. Schilling K, Oberdick J. The treasury of the commons: Making use of public gene expression resources to better characterize the molecular diversity of inhibitory interneurons in the cerebellar cortex. Cerebellum. 2009;8:477-80.

24. Taniguchi H, He M, Wu P, Kim S, Paik R, Sugino K, et al. A resource of Cre driver lines for genetic targeting of GABAergic neurons in cerebral cortex. Neuron. 2011;71:995-1013.

25. Schaper A. The earliest differentiation in the central nervous system of vertebrates. Science. 1897;5:430-1.

26. Athias M. Recherches sur I'histogenese de I'ecorce du cervelet. J Anat Physiol Norm. 1897;33:372-404.

27. Miale IL, Sidman RL. An autoradiographic analysis of histogenesis in the mouse cerebellum. Exp Neurol. 1961;4:277-96.

28. Hallonet MER, Teillet MA, Le Douarin NM. A new approach to the development of the cerebellum provided by the quail-chick marker system. Development. 1990;108:19-31.

29. Feulgen R, Rossenbeck H. Mikroskopisch-chemischer Nachweis einer Nucleinsaüre von Typus der Thymonucleinsaüre und die darauf beruhende elektive Farbung von Zellkernen in mikroskopischen Präparaten. Hoppe Seyler Z Physiol Chem. 1924;135:203-52.

30. Le Douarin NM. Particularités du noyau interphasique chez la caille japonaise (Coturnix coturnix japonica). Utilisation de ces particularités comme marqueur biologique dans les recherches sur 
les interactions tissulaires et les migrations cellulaires au cours de l’ontogenèse. Bull Biol Fr Belg. 1969;103:435-52.

31. Alvarez-Otero R, Sotelo C, Alvarado-Mallart RM. Chick/quail chimeras with partial cerebellar grafts: an analysis of the origin and migration of cerebellar cells. J Comp Neurol. 1993;333:597-615.

32. Lance-Jones CC, Lagernaur CF. A new marker for identifying quail cells in embryonic avian chimeras: a quail specific antiserum. $\mathrm{J}$ Histochem Cytochem. 1987;135:771-80.

33. Napieralski JA, Eisenman LM. Developmental analysis of the external granular layer in the meander tail mutant mouse: do cerebellar microneurons have independent progenitors. Dev Dyn. 1993;197:244-54.

34. Ross ME, Fletcher C, Mason CA, Hatten ME, Heintz N. Meander tail reveals a discrete development unit in the mouse cerebellum. Proc Natl Acad Sci U S A. 1990;87:4189-92.

35. Gao WQ, Hatten ME. Immortalizing oncogenes subvert the establishment of granule cell identity in developing cerebellum. Development. 1994;120:1059-70.

AQ3

36. Zhang L, Goldman JE. Developmental fates and migratory pathways of dividing progenitors in the postnatal rat cerebellum. $\mathrm{J}$ Comp Neurol. 1996;370:536-50.

37. Zhang L, Goldman JE. Generation of cerebellar interneurons from dividing progenitors in white matter. Neuron. 1996;16:47-54.

38. Luskin MB. Restricted proliferation and migration of postnatally generated neurons derived from the forebrain subventricular zone. Neuron. 1993;11:173-89.

39. Jankovski A, Sotelo C. Subventricular zone-Olfactory bulb 
migratory pathway in the adult mouse: cellular composition and specificity as determined by heterochronic and heterotopic transplantation. J Comp Neurol. 1996;371:376-96.

40. Maricich SM, Herrup K. Pax-2 expression defines a subset of GABAergic interneurons and their precursors in the developing murine cerebellum. J Neurobiol. 1999;41:281-94.

41. Cameron DB, Kasai K, Jiang Y, Hu T, Saeki Y, Komuro H. Four distinct phases of basket/stellate cell migration after entering their final destination (the molecular layer) in the developing cerebellum. Dev Biol. 2009;332:309-24.

42. Simat M, Ambrosetti L, Lardi-Studler B, Fritschy JM. GABAergic synaptogenesis marks the onset of differentiation of basket and stellate cells in mouse cerebellum. Eur J Neurosci. 2007;26:2239-56.

43. Sotelo C. Development of "pinceaux" formations and dendritic translocation of climbing fibers during the acquisition of the balance between glutamatergic and gamma-aminobutyric acidergic inputs in developing Purkinje cells. J Comp Neurol. 2008;506:240-62.

44. Erdélyi F, Sekerkova G, Katarova Z, Hájos N, Pálhalmi J, Freund TF, et al. GAD65-GFP transgenic mice expressing GFP in the GABAergic nervous system. FENS Abstr. 2002;1:AO11-3.

45. Mecklenburg N, Garcia-Lopez R, Puelles E, Sotelo C, Martinez S. Cerebellar oligodendroglial cells have a mesencephalic origin. Glia. 2011;59:1946-57.

46. Grimaldi P, Parras C, Guillemot F, Rossi F, Wassef M. Origins and control of the differentiation of inhibitory interneurons and glia in the cerebellum. Dev Biol. 2009;328:422-33.

47. Kita Y, Kawakami K, Takahashi Y, Murakami F. Development of cerebellar neurons and glias revealed by in utero electroporation: 
Golgi-like labeling of cerebellar neurons and glias. PLoS ONE. 2013;8(7):e70091. doi: 10.1371/journal.pone.0070091 .

48. Ben-Arie N, Bellen HJ, Armstrong DL, McCall AE, Gordadze PR, Guo Q, et al. Math1 is essential for genesis of cerebellar granule neurons. Nature. 1997;390:69-172.

49. MacHold R, Fishell G. Math1 is expressed in temporally discrete pools of cerebellar rhombic-lip neural progenitors. Neuron. 2005;48:17-24.

50. Wang VY, Rose MF, Zoghbi HY. Math1 expression redefines the rhombic lip derivatives and reveals novel lineages within the brainstem and cerebellum. Neuron. 2005;48:31-43.

51. Fink AJ, Englund C, Daza RA, Pham D, Lau C, Nivison M, et al. Development of the deep cerebellar nuclei: Transcription factors and cell migration from the rhombic lip. J Neurosci. 2006;26(11):3066-76.

52. Hoshino M, Nakamura S, Mori K, Kawauchi T, Terao M, Nishimura YV, et al. Ptfla, a bHLH transcriptional gene, defines GABAergic neuronal fates in cerebellum. Neuron. 2005;47:201-13.

53. Wechsler-Reya RJ, Scott MP. Control of neuronal precursor proliferation in the cerebellum by Sonic hedgehog. Neuron. 1999;22:103-14.

54. Sudarov A, Turnbull RK, Kim EJ, Lebel-potter M, Guillemot F, Joyner AL. Ascl1 genetics reveals insights into cerebellum local circuit assembly. J Neurosci. 2011;31:11055-69.

55. Huang X, Liu J, Ketova T, Fleming JT, Grover VK, Cooper MK, et al. Transventricular delivery of Sonic hedgehog is essential to cerebellar ventricular zone development. Proc Natl Acad Sci U S A. 2010;107:8422-7. 
56. Fleming JT, He W, Hao C, Ketova T, Pan FC, Wright CCV, et al. The Purkinje neuron acts as a central regulator of spatially and functionally distinct cerebellar precursors. Dev Cell. 2013;27:278-92.

57. Chizhikov VV, Lindgren AG, Currle DS, Rose MF, Monuki ES, Millen KJ. The roof plate regulates cerebellar cell-type specification and proliferation. Development. 2006;133:2793-804.

58. Minaki Y, Nakatani T, Mizuhara E, Inoue T, Ono Y. Identification of a novel transcriptional corepressor, Corl2, as a cerebellar Purkinje cell-selective marker. Gene Expr Patterns. 2008;8:418-23.

59. Leto K, Rolando C, Rossi F. The genesis of cerebellar GABAergic neurons: fate potential and specification mechanisms. Front Neuroanat. 2012. doi: 10.3389/fnana.2012.00006 .

60. Jankovski A, Rossi F, Sotelo C. Neuronal precursors in the postnatal mouse cerebellum are fully committed cells: Evidence from heterochronic transplantations. Eur J Neurosci. 1996;8:2308-19.

61. Hatten ME, Heintz N. Mechanisms of neural patterning and specification in the developing cerebellum. Annu Rev Neurosci. 1995;18:385-408.

62. Yang XW, Zhong R, Heintz N. Granule cell specification in the developing mouse brain as defined by expression of the zinc finger transcription factor RU49. Development. 1996;122:555-66.

63. McConnell SK, Kaznowski CE. Cell cycle dependence of laminar determination in developing neocortex. Science. 1991;254:282-5.

64. Cohen-Tannoudji M, Morello D, Babinet C. Unexpected position-dependent expression of $\mathrm{H}-2$ and $\beta 2$-microglobulin/lacZ 
transgenes. Mol Reprod Dev. 1992;33:149-59.

65. Oberdick J, Schilling C, Smeyne RJ, Corbin JG, Bocchiaro C, Morgan JI. Control of segment-like patterns of gene expression in the mouse cerebellum. Neuron. 1993;10:1007-18.

66. Forss-Petter S, Danielson PE, Catsicas S, Battenberg E, Price J, Nerenberg $\mathrm{M}$, et al. Transgenic mice expressing $\beta$ galactosidase in mature neurons under neuron-specific enolase promoter control. Neuron. 1990;5:187-97.

67. Carletti B, Grimaldi P, Magrassi L, Rossi F. Specification of cerebellar progenitors after heterotopic-heterochronic transplantation to the embryonic CNS in vivo and in vitro. J Neurosci. 2002;22:7132-46.

68. Leto K, Carletti B, Williams IM, Magrassi L, Rossi F. Different types of cerebellar GABAergic interneurons originate from a common pool of multipotent progenitor cells. J Neurosci. 2006;26:11682-94.

69. Rolando C, Gribaudo S, Yoshikawa K, Leto K, De Marchis S, Rossi F. Extracerebellar progenitors grafted to the neurogenic milieu of the postnatal cerebellum adapt to the host environment but fail to acquire cerebellar identities. Eur J Neurosci. 2010;31:1340-51.

70. Leto K, Bartolini A, Yanagawa Y, Obata K, Magrassi L, Schilling K, et al. Laminar fate and phenotype specification of cerebellar GABAergic interneurons. J Neurosci. 2009;27:7079-91.

71. Celio MR, Haizmann CW. Calcium-binding protein parvalbumin as a neuronal marker. Nature. 1981;293:300-2.

72. Milosevic A, Noctor SC, Martinez-Cerdeno V, Kriegstein AR, Goldman JE. Progenitors from the postnatal forebrain subventricular zone differentiate into cerebellar-like interneurons and cerebellarspecific astrocytes upon transplantation. Mol Cell Neurosci. 
73. Eccles JC, Llinas R, Sasaki K. The excitatory synaptic action of climbing fibers on Purkinje cells of the cerebellum. J Physiol. 1966;182:268-96.

74. Palay SL, Chan-Palay V. Cerebellar Cortex Cytology and Organization. Berlin: Springer; 1974.

75. Yan XX, Ribak CE. Developmental expression of gammaaminobutyric acid transporters (GAT-1 and GAT-3) in the rat cerebellum: evidence for a transient presence of GAT-1 in Purkinje cells. Brain Res. 1998;111:253-69.

76. Rosina A, Morara S, Provini L. GAT-1 developmental expression in the rat cerebellar cortex: Basket and pinceau formation. Neuroreport. 1999;10:1613-8.

77. Ango F, di Cristo G, Higashiyama H, Vann Bennett $\mathrm{P}$, Wu P, Huang ZJ. Ankyrin-based subcellular gradient of neurofascin, an immunoglobulin family protein, directs GABAergic innervation at Purkinje axon initial segment. Cell. 2004;119:257-72.

78. Takayama C, Inoue Y. Developmental expression of GABA transporter- 1 and 3 during formation of the GABAergic synapses in the mouse cerebellar cortex. Dev Brain Res. 2005;158:41-9.

79. Chedotal A, Sotelo C. The "creeper stage" in cerebellar climbing fiber synaptogenesis precedes the "pericellular nest". Ultrastructural evidence with parvalbumin immunocytochemistry. Dev Brain Res. 1993;76:207-20.

80. Morara S, van der Want JJL, de Weerd H, Provini L, Rosina A. Ultra-structural analysis of climbing fiber-Purkinje cell synaptogenesis in the rat cerebellum. Neuroscience. 2001;108:655-71. 
81. West MJ, del Cerro M. Early formation of synapses in the molecular layer of the fetal rat cerebellum. J Comp Neurol. 1976;165:137-53.

82. Ben-Ari Y. Excitatory actions of GABA during development: the nature of the nurture. Nat Rev Neurosci. 2002;3:728-39.

83. Eilers J, Plant TD, Marandi N, Konnerth A. GABA-mediated $\mathrm{Ca} 2+$ signaling in developing rat cerebellar Purkinje cells. J Physiol. 2001;536:429-37.

84. Rivera C, Voipio J, Payne JA, Ruusuvuori E, Lahtinen H, Lamsa $\mathrm{K}$, et al. The $\mathrm{K}+/ \mathrm{Cl}$ - co-transporter $\mathrm{KCC} 2$ renders GABA hyperpolarizing during neuronal maturation. Nature. 1999;397:251-5.

85. Marty S, Wehrlé R, Alvarez-Leefmans FJ, Gasnier B, Sotelo C. Postnatal maturation of $\mathrm{Na}+, \mathrm{K}+, 2 \mathrm{Bl}$ - cotransporter expression in inhibitory synaptogenesis in the rat hippocampus: an immunocytochemical analysis. Eur J Neurosci. 2002;15:233-45.

86. Yamada J, Okabe A, Toyoda H, Kilb W, Luhmann HJ, Fukuda A. Cl- uptake promoting depolarizing GABA actions in immature rat neocortical neurons is mediated by NKCC1. J Physiol. 2004;557:829-41.

87. Lee H, Chen CX, Liu YJ, Aizenman E, Kandler K. KCC2 expression in immature rat cortical neurons is sufficient to switch the polarity of GABA responses. Eur J Neurosci. 2005;21:2593-9.

88. Gobel S. Axo-axonic septate junctions in the basket formation of the cat cerebellar cortex. J Cell Biol. 1971;51:328-33.

89. Sotelo C, Llinás R. Specialized membrane junctions between neurons in the vertebrate cerebellar cortex. J Cell Biol. 1972;53:271-89. 
90. Bourrat F, Sotelo C. Postnatal development of the inferior olivary complex in the rat. I. An electron microscopic study of the medial accessory olive. Brain Res. 1983;284(2-3):291-310.

91. Gotow T, Sotelo C. Postnatal development of the inferior olivary complex in the rat: IV. Synaptogenesis of GABAergic afferents, analyzed by glutamic acid decarboxylase immunocytochemistry. J Comp Neurol. 1987;263:526-52.

92. Buttermore ED, Piochon C, Wallace ML, Philpot BD, Hansel C, Bhat MA. Pinceau organization in the cerebellum requires distinct functions of neurofascin in Purkinje and basket neurons during postnatal development. J Neurosci. 2012;32:4724-42.

93. Ango F, Wu C, van der Want JJ, Wu P, Schachner M, Huang ZJ. Bergmann glia and the recognition molecule CHL1 organize GABAergic axons and direct innervation of Purkinje cell dendrites. PLoS Biol. 2008. doi: 10.1371/journal.pbio.0060103 .

94. Cioni JM, Telley L, Saywell V, Cadilhac C, Jourdan C, Huber $\mathrm{AB}$, et al. SEMA3A signaling controls layer-specific interneuron branching in the cerebellum. Curr Biol. 2013;23:850-61.

95. Chan-Palay V, Palay SL. Interrelations of basket cell axons and climbing fibers in the cerebellar cortex of the rat. Z Anat EntwicklGesch. 1970;132:191-227.

96. Llinás R, Sugimori M. Calcium conductances in Purkine cell dendrites: their role in development and integration. Prog Brain Res. 1979;51:323-34.

97. Viltono L, Patrizi A, Fritschy JM, Sassoè-Pognetto M. Synaptogenesis in the cerebellar cortex: differential regulation of gephyrin and GABA-A receptors at somatic and dendritic synapses of Purkinje cells. J Comp Neurol. 2008;508:579-91.

98. Larramendi LMH. Analysis of synaptogenesis in the cerebellum 
of the mouse. In: Llinás R, editor. Neurobiology of Cerebellar Evolution and Development. Chicago: AMA-ERF Institute for Biomedical Research; 1969. p. 803-43.

99. Cajal SR. Nouvelles Idées sur la Structure du Système Nerveux chez l'Homme et chez les Vertébrés. Paris: C Reinwald \& Cie; 1894.

100. Eccles JC, Llinas R, Sasaki K. Parallel fibre stimulation and the responses induced thereby in the Purkinje cells of the cerebellum. Exp Brain Res. 1966;1:17-39.

101. Eccles JC, Llinas R, Sasaki K. The mossy fibre-granule cell relay of the cerebellum and its inhibitory control by Golgi cells. Exp Brain Res. 1966;1:82-101.

102. Sotelo C, Camillo G, Cajal SR. The anatomical organization of the cortex of the cerebellum. Can the neuron doctrine still support our actual knowledge on the cerebellar structural arrangement? Brain Res Rev. 2011;66:16-34.

103. Fuxe K. Evidence for the existence of monoamine containing neurons in the central nervous system. IV. Distribution of monoamine nerve terminals in the central nervous system. Acta Physiol Scand. 1965;247 Suppl 64:7-85.

104. Hökfelt T, Fuxe K. Cerebellar monoamine nerve terminals, a new type of afferent fibers to the cortex cerebelli. Exp Brain Res. 1969;9:63-72.

105. Mugnaini E, Dahl AL. Mode of distribution of aminergic fibers in the cerebellar cortex of the chicken. J Comp Neurol. $1975 ; 162: 417-32$.

106. Beaudet A, Sotelo C. Synaptic remodeling of serotonin axon terminals in rat agranular cerebellum. Brain Res. 1981;206:305-29.

107. Abbott LC, Sotelo C. Ultrastructural analysis of 
catecholaminergic innervation in weaver and normal mouse cerebellar cortices. J Comp Neurol. 2000;426:316-29.

108. Lugaro E. Sulle connessioni tra gli elementi nervosi della corteccia cerebellare con considerazioni generali sul significato fisiologico dei rapporti tra gli elementi nervosi. Riv Sper Freniatr Med Leg. 1894;20:297-331.

109. Middleton FA, Strick PL. Anatomical evidence for cerebellar and basal ganglia involvement in higher cognitive functions. Science. 1994;266:458-61.

110. Schmahmann JD. The role of the cerebellum in cognition and emotion: Personal reflections since 1982 on the dysmetria of thought hypothesis, and its historical evolution from theory to therapy. Neuropsychol Rev. 2010;20:236-60.

111. Sotelo C. Viewing the cerebellum through the eyes of Ramon $y$ Cajal. Cerebellum. 2008;7:517-22.

112. Larramendi LMH, Lemkey-Johnston N. The distribution of recurrent Purkinje collateral synapses in the mouse cerebellar cortex. J Comp Neurol. 1970;138:451-82.

113. Lemkey-Johnston N, Larramendi MLH. Types and distribution of synapses upon basket and stellate cells of the mouse cerebellum: an electron microscopic study. J Comp Neurol. 1968;134:73-112.

114. Lainé J, Axelrad H. Lugaro cells target basket and stellate cells in the cerebellar cortex. Neuroreport. 1998;9:2399-403.

115. Lainé J, Axelrad H. Extending the cerebellar Lugaro cell class. Neurosci. 2002;115:363-74.

116. Yamazaki M, Araki K, Shibata A, Mishina M. Molecular cloning of a cDNA encoding a novel member of the mouse glutamate receptor channel family. Biochem Biophys Res Commun. 
117. Konno K, Matsuda K, Nakamoto C, Uchigashima M, Miyazaki T, Yamasaki M, et al. Enriched expression of GluD1 in higher brain regions and its involvement in parallel fiber-interneuron synapse formation in the cerebellum. J Neurosci. 2014;34:7412-24.

118. Kashiwabuchi N, Ikeda K, Araki K, Hirano T, Shibuki K, Takayama $\mathrm{C}$, et al. Impairment of motor coordination Purkinje cell synapse formation and cerebellar long-term depression in GluR $\delta 2$ mutant mice. Cell. 1995;81:245-52.

119. Lalouette A, Lohof A, Sotelo C, Guénet J, Mariani J. Neurobiological effects of a null mutation depend on genetic context: comparison between two hotfoot alleles of the delta-2 ionotropic glutamate receptor. Neuroscience. 2001;105:443-55.

120. Kaiserman-Abramof IR, Palay SL. Fine structural studies of the cerebellar cortex in a mormyrid fish. In: Llinás R, editor. Neurobiology of cerebellar evolution and development. Chicago: AMA-ERF Institute for Biomedical Research; 1969. p. 171-205.

121. Dumoulin A, Triller A, Dieudonné S. IPSC kinetics at identified GABAergic and mixed GABAergic and glycinergic synapses onto cerebellar Golgi cells. J Neurosci. 2001;21:6045-57.

122. Geurts FJ, De Schutter E, Dieudonné S. Unraveling the cerebellar cortex: cytology and cellular physiology of large-sized interneurons in the granular layer. Cerebellum. 2003;2:290-9.

123. Dugué GP, Brunel N, Hakim V, Schwartz E, Chat M, Lévesque $\mathrm{M}$, et al. Electrical coupling mediates tunable low-frequency oscillations and resonance in the cerebellar Golgi cell network. Neuron. 2009;61:126-39.

124. D'Angelo E, de Zeeuw CI. Timing and plasticity in the cerebellum: focus on the granular layer. Trends Neurosci. 
$2009 ; 32: 30-9$.

125. Hull C, Regehr WG. Identification of an inhibitory circuit that regulates cerebellar Golgi cell activity. Neuron. 2012;73:149-58.

126. Dieudonné S, Dumoulin A. Serotonin-driven long-range inhibitory connections in the cerebellar cortex. J Neurosci. 2000;20:1837-48.

127. Palay SL. The structural basis for neural action. In: Brazier MAB, editor. Brain function. Vol. II RNA and brain function; memory and learning, UCLA Forum of medical sciences. Los Angeles: University of California Press; 1964. p. 69-108.

128. Palay SL, Sotelo C, Peters A, Orkand PM. The axon hillock and the initial segment. J Cell Biol. 1968;38:193-201.

129. Somogyi P, Hámori J. A quantitative electron microscopic study of the Purkinje cell axon initial segment. Neuroscience. 1976;1:361-5.

130. Iwakura A, Uchigashima M, Miyazaki T, Yamasaki M, Watanabe M. Lack of molecular-anatomical evidence for GABAergic influence on axon initial segment of cerebellar Purkinje cells by the pinceau formation. J Neurosci. 2012;32:9438-48.

131. Laube G, Roper J, Pitt JC, Sewing S, Kistner DU, Garner CC, et al. Ultrastructural localization of Shaker-related potassium channel subunits and synapse-associated protein 90 to septate-like junctions in rat cerebellar pinceaux. Mol Brain Res. 1996;42:51-61.

\section{Bobik M, Ellisman MH, Rudy B, Martone ME. Potassium} channel subunit Kv3.2 and the water channel aquaporin-4 are selectively localized to cerebellar pinceau. Brain Res. 2004;1026:168-78.

133. Furukawa T, Furshpan EJ. Two inhibitory mechanisms in the 
Mauthner neurons of goldfish. J Neurophysiol. 1963;26:140-76.

134. Triller A, Korn H. Glio-axonic junctional like complexes at the Mauthner cell's axon cap of teleosts: a possible morphological basis for field effect inhibitions. Neurosci Lett. 1980;18:275-81.

135. Korn H, Axelrad H. Electrical inhibition of Purkinje cells in the cerebellum of the rat. Proc Natl Acad Sci U S A. $1980 ; 77: 6244-7$.

136. Blot A, Barbour B. Analysis of the study of the cerebellar pinceau by Korn and Axelrad. Preprint at: http://biorxiv.org/content /early/2013/12/03/001123 .

137. Blot A, Barbour B. Ultra-rapid axon-axon ephatic inhibition of cerebellar Purkinje cells by the pinceau. Nat Neurosci. 2014;17:289-95.

138. Baker R, Llinas R. Electrotonic coupling between neurones in the rat mesencephalic nucleus. J Physiol. 1971;212:45-63.

139. Sotelo C, Korn H. Morphological correlates of electrical and other interactions through low-resistance pathways between neurons of the vertebrate central nervous system. In: Bourne GH, Danielli JF, Jeon KW, editors. International review of cytology, vol. 55. London: Academic; 1978. p. 67-107.

140. Revel JP, Karnovsky MJ. Hexagonal arrays of subunits in intercellular junctions of the mouse heart and liver. J Cell Biol. 1967;33:C7-12.

141. Bennett MVL. Physiology of electrotonic junctions. Ann N Y Acad Sci. 1966;137:509-39.

142. Loewenstein WR. Permeability of membrane junctions. Ann N Y Acad Sci. 1966;137:441-72. 
143. Gilula NB, Reeves OR, Steinbach A. Metabolic coupling, ionic coupling and cell contacts. Nature. 1972;235:262-5.

144. Pitts JD, Simms JW. Permeability of junctions between animal cells: Intercellular transfer of nucleotides but not macromolecules. Exp Cell Res. 1977;104:153-63.

145. Simpson I, Rose B, Loewenstein WR. Size limit of molecules permeating the junctional membrane channels. Science. 1977;195:294-6.

146. Goodenough DA, Dick 2nd JS, Lyons JE. Lens metabolic cooperation: a study of mouse lens transport and permeability visualized with freeze-substitution autoradiography and electron microscopy. J Cell Biol. 1980;86:576-89.

147. Söhl G, Maxeiner S, Willecke K. Expression and function of neuronal gap junctions. Nat Rev Neurosci. 2005;6:191-200.

148. Sotelo C, Triller A. Fate of presynaptic afferents to Purkinje cells in the adult "nervous" mutant mouse. A model to study presynaptic stabilization. Brain Res. 1979;175:11-36.

149. Belluardo N, Mudò G, Trovato-Salinaro A, Le Gurun S, Charollais A, Serre-Beinier V, et al. Expression of connexin 36 in the adult and developing rat brain. Brain Res. 2000;865:121-38.

150. Van Der Giessen RS, Koekkoek SK, van Dorp S, De Gruijl JR, Cupido A, Khosrovani S, et al. Role of olivary electrical coupling in cerebellar motor learning. Neuron. 2008;58:599-612.

151. Alcami P, Marty A. Estimating functional connectivity in an electrically coupled interneuron network. Proc Natl Acad Sci U S A. 2013;110:E4798-807.

152. Rela L, Szczupak L. Gap junctions: their importance for the dynamics of neural circuits. Mol Neurobiol. 2004;30:341-57. 
153. Kim J, Lee S, Tsuda S, Zhang X, Asrican B, Gloss B, et al. Optogenetic mapping of cerebellar inhibitory circuitry reveals spatially biased coordination of interneurons via electrical synapses. Cell Rep. 2014;7:1601-13. 